Espacio y Desarrollo $\mathrm{N}^{\circ} 35,2020$, pp. 7-38 (e-ISSN 2311-5734)

https://doi.org/10.18800/espacioydesarrollo.202001.001

\title{
Notas PARA PENSAR LA CONFLICTIVIDAD SOCIOAMBIENTAL EN CLAVE TERRITORIAL
}

\author{
Facundo M. Hernández \\ https://orcid.org/0000-0003-0493-2481 \\ CONICET - CIGSA - UNMdP, Argentina \\ fmhernandez12@yahoo.com.ar
}

Fecha de recepción: 27/06/2020

Fecha de aceptación: 18/12/2020

\begin{abstract}
Resumen
El presente trabajo aborda el problema socioambiental tomando como base la geografía crítica, corriente necesaria en un contexto de crisis socioambientales que ponen de manifiesto las contradicciones y límites del sistema capitalista en América Latina y el mundo. Desde este posicionamiento, la propuesta es introducir a la temática atendiendo a la territorialidad que contiene la relación sociedad-naturaleza. Se hace énfasis en la tendencia, bajo la lógica de la economía de mercado, a que se desencadenen conflictos socioambientales incitados por agrupamientos sociales con intereses ambientales y demás organizaciones territoriales que pugnan por los recursos, la naturaleza, los territorios y la democracia. Además, estos movimientos sociales en su accionar contribuyen al estado del conocimiento de los casos en los que se involucran y promueven la instalación en la agenda pública de temas censurados, inadvertidos o tergiversados por las corporaciones mediáticas y las agencias de gobierno. El aporte de estas líneas es revisar conceptos, reinterpretarlos, ensayar métodos de trabajo y organizarlos para fines didácticos, con el fin de estimular una conciencia crítica de lo ambiental y territorial en alumnos de los niveles educativos en los que se imparta la geografía. En todo el artículo, se trabajó con diferentes ejemplos que sirven para clarificar los términos propuestos y las cuestiones de método. Palabras clave: dinámica territorial, problemáticas socioambientales, fracturas ecosistémicas, racionalidad capitalista.
\end{abstract}

\section{Notes to think socio-environmental conflictivity in territorial key}

\section{Abstract}

This paper addresses the socio-environmental problem from Critical Geography, a necessary current in a context of socio-environmental crises that express the contradictions and limits of the capitalist system in Latin America and the world. From this position, the proposal 
is to introduce the subject considering the territoriality that the society-nature relationship contains. Emphasis is placed on the tendency, under the logic of the market economy, for socio-environmental conflicts to be triggered by social groups with environmental interests and other territorial organizations that fight for resources, nature, territories, and democracy. These social movements in their actions contribute to the knowledge of the cases in which they become involved and promote the installation on the public agenda of topics censored, unnoticed or misrepresented by the media and government agencies. The contribution of these lines is to review concepts, reinterpret them, rehearse working methods, and organize them for didactic purposes, in order to stimulate a critical awareness of the environmental and territorial in students at the educational levels in which Geography is taught. Throughout the article, different examples were used to clarify the proposed terms and method questions.

Keywords: territorial dynamics, socio-environmental problems, ecosystem fractures, capitalist rationality.

\section{INTRODUCCIÓN}

El presente artículo está dividido en tres partes, la primera de ellas es un aporte reflexivo y conceptual al estado de crisis socioambiental que distingue los tiempos actuales. Se expone, en los primeros apartados, los motivos por los cuales consideremos que el campo geográfico aporta al estudio de las problemáticas socioambientales y la conflictividad creciente mediante la elaboración de un enfoque territorial para tal fin. Se presenta, como punto de partida, las contribuciones a la conceptualización de territorio presentes en la obra del geógrafo brasileño Rogério Haesbaert que habilita a ahondar en la relación trialéctica sociedad-naturaleza-territorio. En la segunda parte, con base en el tratamiento conceptual, se presenta una propuesta metodológica, inspirada en los aportes del geógrafo suizo Claude Raffestin, que tiene como finalidad contribuir en el estudio de la dinámica en el territorio y los múltiples factores que activan transformaciones en el mismo, enfatizando en los cambios asociados a problemáticas y conflictos socioambientales. La propuesta ensayada, se promueve como una herramienta de estudio que refleja la esencia diacrónica en la construcción territorial, la transformación constante y la importancia que tiene esta propiedad para el estudio de la conflictividad socioambiental, entendiendo esto último como resultado de un proceso histórico y de las contradicciones inherentes de los sistemas hegemónicos. Por último, el trabajo se cierra con un aporte didáctico consistente en una serie de ejercicios para aplicar y discutir con lo expuesto en el artículo, con aplicabilidad en diferentes niveles educativos.

Se destaca, en todo el cuerpo del texto, las citas de casos históricos emblemáticos y otros de actualidad, que contribuyan a fijar la propuesta y la discusión en torno a la misma. Además, se efectuó una selección fotográfica cuidadosa que grafique los conflictos elegidos como ejemplos. 


\section{LO CONCEPTUAL EN UN ENFOQUE TERRITORIAL CRÍTICO}

El presente trabajo es un aporte conceptual y didáctico para el estudio de las tensiones socioambientales desde un enfoque territorial. Esto significa que el andamiaje reflexivo, sobre el cual se funda la propuesta, no se centrará estrictamente sobre la dimensión ambiental ${ }^{1}$. Sin dejar de reconocer la importancia de la información y el dato ambiental, que permiten dar dimensión a una problemática ambiental o medir la superación o no de los umbrales aceptables, en la perspectiva propuesta descartamos la noción $<<$ naturista $>>$ de territorio. El concepto al que se adhiere es aquel que propone una concepción integral y multidimensional.

El ángulo en el que se desenvuelve el determinismo ambiental conduce a pensar genéricamente al hombre como responsable de las crisis ambientales. Esta idea, en los planteamientos más radicalizados, se vigoriza al atribuirle al género humano un instinto basado en la competitividad y capacidad destructiva. Aun utilizado en la bibliografía geográfica y en manuales escolares, el determinismo ambiental se desenvuelve en posiciones teóricas como las de Ardrey (2014) quien considera que los hombres «actúan de la forma que lo hacen por razones del pasado evolutivo, no por su presente cultural». En el campo geográfico, estas perspectivas se fundan en las contribuciones positivistas de Carl Ritter y Friedrich Ratzel en el siglo XIX. Estas posiciones se labraron en un contexto geográfico signado por las pugnas y expansiones imperialistas y colonizadoras. Friedrich Ratzel entendía que el ser humano y las sociedades son objetos del medio natural, y que sus múltiples manifestaciones debían explicarse con base en las circunstancias geográficas exteriores (Ratzel, 1987). De esta forma, una corriente geográfica, en ese período histórico, exponía argumentos para reafirmar la penetración de las metrópolis en las colonias.

Cabe subrayar que no se desconoce la importancia de la «dimensión natural» del territorio, ya que la misma es elemental porque, en todos los casos, se revela como un componente fundamental, aunque nunca en forma disociada del resto. No es correcto confundir la «dimensión ambiental», que todo territorio contiene, con el «determinismo ambiental» que predominó en la geografía de fines de siglo XIX y principios de XX, y que hoy en día encuentra alguna referencia en manuales escolares y textos científicos. En definitiva, a lo que se adhiere es que la naturaleza no determina el comportamiento social, actúa como condicionante. De la misma manera el hombre, en su desarrollo técnico conducente a dominar y transformar cada vez más el medio natural, nunca

\footnotetext{
1 Los trabajos centrados únicamente en la dimensión ambiental orientan a las investigaciones hacia una búsqueda de datos técnicos y estadísticas que den cuenta de los impactos en los ecosistemas urbanos, rurales o naturales, por el accionar antrópico, a través de la medición de indicadores de contaminación, erosión, desertificación, etc. Es necesario, complementar este enfoque con uno más amplio si lo que se pretende es tener una visión holística
} 
llega a hacerlo por completo, lo condiciona en diferentes grados, intensidades y escalas. Una de las formas de expresar esta relación es evaluar en qué medida los sistemas naturales son agotados frente a las exigencias de los sistemas socioeconómicos, y cómo esa consunción de los ecosistemas engendra situaciones de degradación socioambiental de las que emergen necesidades que estaban (parcialmente) satisfechas (por ejemplo, la relación entre la megaminería y la escasez de agua debido a los volúmenes que demanda la actividad) y se agudizan las vulnerabilidades preexistentes que exigen nuevas respuestas sociales que pueden acarrear nuevos impactos socioambientales. Esto refleja qué tan compleja es la sociabilización de la naturaleza y las tensiones permanentes y acumulables en la relación sociedad-naturaleza, sobre todo en un sistema económico que, para sobrevivir a sus crisis cíclicas, tiene que expandirse ilimitadamente en un mundo de recursos finitos.

El concepto de territorio que guiará el enfoque se basa en el propuesto por Haesbaert (2004) quien lo considera como aquel que «envuelve una dimensión simbólica, cultural, a través de una identidad territorial atribuida por los grupos sociales, como control simbólico sobre el espacio donde viven, ... Por lo tanto, es una forma de apropiación, ... Y una dimensión más concreta, de carácter político-económico: la apropiación y ordenación del espacio como forma de dominio y disciplinarización de los individuos» y de los medios naturales, devenidos en recursos territoriales. A estas dos dimensiones se le añade una "dimensión vital», en la que se desenvuelven factores bióticos y abióticos, existentes o introducidos por fuerzas sociales, que interactúan facilitando, obstaculizando, neutralizando, e impidiendo los procesos de apropiación y/o significación concretados o pensados; pasados, actuales o proyectados. Esta dimensión, es la existencia orgánica e inorgánica, más allá de los límites del territorio íntimo (el cuerpo humano) con el que interactúa para generar beneficios o perjuicios. Lo vital, es el soporte de vida de un espacio social, son las interacciones ecosistémicas que se reproducen en el espacio apropiado y ordenado según las posibilidades, intenciones, criterios de los grupos sociales.

Siguiendo a Haesbaert (2004), todo territorio es «funcional y simbólico, pues las relaciones de poder tienen en el espacio un componente inseparable tanto de la realización de funciones como de la producción de significados». También es orgánico, en tanto lo vivo y lo no vivo, los objetos sociales y los naturales, cada uno con una función asignada (heredada o asignada) interactúan entre sí, y conforman una unidad territorial que tiene cierto orden dinámico, más o menos inestable, ya que en algún momento es impactado, distorsionado y/o discutido, y reordenado con base en las intenciones, las consecuencias y las formas existentes que accionan sobre los objetos y los procesos. Por último, cabe destacar que los territorios creados a partir de una definición o delimitación del espacio son abiertos, debido a que interactúan con otras unidades territoriales por múltiples razones (tensión, cooperación, intercambio) que 
conducen a que puedan colisionarse, colapsarse, anexarse, solaparse, segregarse. Por ser el proceso de dominación y/o apropiación un continuo, «se requiere que el territorio y la territorialización sean trabajados en la multiplicidad de sus manifestaciones, que es multiplicidad de poderes incorporados a través de los múltiples sujetos involucrados» (Haesbaert, 2004) y de los medios y elementos existente (sociales y naturales).

El territorio entraña relaciones sociales de apropiación, control, dominio y significación que se construyen en el tiempo y en el espacio. Esto presupone que no está fijo, ya que por ser relacional «es movimiento, fluidez, interconexión» (Haesbaert, 2004, p. 93). Una de las características más importantes es su historicidad, el cómo se construye. La construcción del territorio es, en parte, la evolución histórica de las formas en que las diferentes generaciones han organizado el territorio al que tienen acceso, poder y control, todas ellas partiendo de una base histórica natural, que deja de ser preponderante cuando las relaciones sociales penetran y progresan en su configuración, quebrando la unidad previa del mundo natural primitivo y dando paso a la regulación de las instituciones sociales (Pujol, 1987).

El ejercicio de crear, definir, reconocer y controlar territorios — la territorialidadno implica que la sociedad actúa en conjunto con el mismo grado de control, como si el orden y la identidad fuese un consenso mecánico, sino que son determinados actores sociales los que tienen una mayor injerencia sobre la configuración y significación territorial. Esto permite concluir que algunos actores sociales ejercen su territorialidad sobre otros, mediante el consenso o una supuesta legitimidad otorgada por el conjunto, o la directa imposición, mediante mecanismos opresivos y coercitivos. El ejercicio del poder (Foucault, 1990) les permite a determinados grupos o individuos sociales ser actores dominantes o hegemónicos en el proceso de construcción territorial; mientras que otros, sujetos de control de los primeros, se vuelven actores subalternos (Gramsci, 1996). Estos últimos, en algún u otro momento de la historia, intentan, en una unidad territorial, desplazar a los hegemónicos. Desde este ángulo, se puede afirmar que toda lucha de clases, de movimientos obreros, sociales y ambientales, de género, de disidencias sexuales, de Estados, de partidos políticos, por los Derechos Humanos, entre otros, son, también, una pugna por lo territorial.

\section{El problema socioambiental desde y en los territorios}

Como ya se ha mencionado, todo proceso de construcción contiene la historia natural como etapa pre sociabilizada del territorio en la que el gobierno sobre las relaciones de ocupación y apropiación está estrictamente ligado a la dinámica natural y a la lucha por la supervivencia (Darwin, 2014). En esta etapa, el territorio tiene un sentido puramente ecosistémico, en el que interactúan los factores bióticos y abióticos sin mediación significativa de las sociedades humanas. Las relaciones que predominan están 
libradas a los instintos de conservación, reproducción y dominación de las especies que habitan y construyen el territorio. Se trata de una territorialidad definida por la capacidad de las especies de controlar su propio espacio, a fin de reproducir su existencia. Es la concepción, en términos de Di Méo (1998), más primitiva de territorio como «espacio defendido por todo animal confrontado con la necesidad de protegerse». Esta concepción se asocia al concepto ecológico de $<<$ nicho $>>$. El territorio natural, a través de los tiempos biológicos y geológicos, se transforma a sí mismo y a las especies que lo habitan, dependiendo de su capacidad de adaptación que resulta de la selección natural (Darwin, 2014). En efecto, el hombre le imprime al territorio su historia cuando se sedentariza, cuando controla superficies que lo abrigan y les proveen recursos, con la zonificación de la caza, la domesticación y el cultivo. Cuando el territorio es construido históricamente por las sociedades humanas este asume cualidades diferentes, lo que no significa que se elimina lo natural, ya que se mantienen mecanismos del funcionamiento ecosistémico que condicionan el desarrollo territorial de los grupos sociales, pero al mismo tiempo esa dinámica natural se encuentra condicionada por la misma comunidad que ha intervenido e inventado el territorio, ahora como constructo social o, mejor aún, socioambiental.

En el pasaje del territorio como constructo natural a socioambiental, radica la problemática socioambiental, que es, en consecuencia, un problema social. Desde que las sociedades humanas intentar acumular excedentes del medio, sustituir el valor de uso por el valor de cambio, y desarrollar asentamientos y unidades de producción cada vez más intensivas y extensivas tendientes a liquidar la herencia ecológica, los territorios creados expresan tensiones en la relación sociedad-naturaleza. No es posible entender el problema socioambiental como resultado de un accionar irracional. Estas valoraciones sustentan buena parte de la bibliografía sobre la temática, desde la Conferencia de Estocolmo de $1972^{2}$ hasta la Cumbre de París de $2015^{3}$. En la línea argumentativa de los organismos supranacionales, habría que reconocer que hay un ethos en la historia de la humanidad impulsado por un irracional uso de los recursos naturales y no por la racionalidad de un sistema de producción y explotación. Es la razón la que permite el control y manejo de las fuerzas naturales para el beneficio humano. Todo modelo de producción, en sus diferentes fases históricas, presenta su racionalidad propia, por tal motivo, no es la «irracionalidad» el problema sino las contrariedades que se derivan de

\footnotetext{
2 Se trató de la Conferencia de Naciones Unidas sobre el Medio Humano, celebrada en Estocolmo, Suecia, entre el 5 y 16 de junio de 1972, en la que se deliberó sobre la problemática ambiental y se redactaron una serie de principios comunes que «ofrezcan a los pueblos del mundo inspiración y guía para preservar y mejorar el medio humano».

3 Se trató de la Conferencia de las Naciones Unidas sobre Cambio Climático, celebrada en París, entre el 30 de noviembre y el 11 de diciembre de 2015, en la que se estableció un acuerdo entre las naciones firmantes que establece medidas para la reducción de las emisiones de Gases de Efecto Invernadero.
} 
una racionalidad determinada. En todo caso, como sugiere Leff (2004), es más idóneo plantear «la crisis de la racionalidad moderna o capitalista».

La evolución histórica de la humanidad y, principalmente, el desarrollo material de las fuerzas de producción hace ficticio pensar que pueden existir territorios que no atraviesen algún tipo de problema socioambiental. En primer lugar, porque cada porción de la superficie terrestre forma parte de un ecosistema planetario, por tal motivo, ciertos impactos acontecidos en un espacio delimitado pueden ingresar a la circulación atmosférica u oceánica y expandirse en amplias escalas, alcanzando territorios sin intervenciones antrópicas directas (por ejemplo, el derretimiento de los cascos polares producto del incremento del calentamiento global). Lo interesante es que no es el conjunto de la humanidad la que reproduce, amplifica y profundiza la conflictividad socioambiental, no se trata de una sumatoria de actos individuales «irracionales». En efecto, la crisis ecológica es producto de la necesidad expansiva del capital que, como destaca Kovel (2005), "puede demostrarse empíricamente, mediante la localización de las fracturas ecosistémicas por la acción de las corporaciones o agencias gubernamentales que operan y se realizan en territorios bajo la influencia del campo de fuerzas del capital».

En un mundo en el que el sistema capitalista alcanza su dimensión global, resulta ilusorio suponer que la tasa de acumulación y la aceleración de la tasa de rotación, que son conseguidas mediante la superexplotación de los recursos naturales y humanos, el consumo banal o la programación en forma obsoleta y percibida de bienes materiales, no actúen destructivamente sobre el medio ambiente. Por otro lado, el socialismo del siglo XX, que se desarrolló bajo la égida del estanilismo y la burocratización del Estado, también fracasó en términos ambientales. En los países de la periferia soviética y en la ex URSS, las fracturas ecosistémicas se reprodujeron, en algunos casos, con mayor intensidad que en el capitalismo occidental, prueba de ello es el accidente nuclear de Chérnobyl en 1986, en un contexto dominado por la Guerra Fría. El régimen soviético no llegó a esbozar una reestructuración tecnológica para atenuar los problemas ambientales derivados de la contaminación, develando una contradicción que no pudo ser superada por aquellos que se suponía superarían las contradicciones y limitaciones del capitalismo ${ }^{4}$.

Al margen de como tributaron los ex estados soviéticos al problema ambiental mundial, no hay duda de la hegemonía de la economía de mercado en el actual contexto de globalización, incluso hay países en los que se asiste a una restauración

\footnotetext{
4 La contradicción que adquiere una mayor notoriedad en el régimen soviético, en la problemática abordada, es aquella que se desprende de haber contado con un sistema de salud pública, de libre acceso y de calidad, y una salubridad ambiental degradada en las ciudades más impactadas por la industrialización, en un contexto de competencia mundial con las potencias capitalistas-occidentales. Esto condujo a un deterioro de las condiciones de vida que antagonizaban con los valores de la Revolución de Octubre.
} 
capitalista, aún bajo gobiernos centralizados en un único partido político (como China o Vietnam ${ }^{5}$ ). Como el capitalismo es un sistema de relaciones sociales que se basa en la división en clases de la sociedad y en la asimetría entre ellas, es correcto plantear que la clase trabajadora, el campesinado y las masas de desempleados — la mayoría de la humanidad- están más afectados a las consecuencias que trae aparejada la crisis ecológica que aquellos que son responsables de la misma. En determinados episodios espaciotemporales, la crisis se cobra las vidas de los sectores más vulnerabilizados por el grado de exposición al que son expuestos. Incluso la desigualdad que entraña el sistema contribuye a ensanchar la brecha socioambiental entre las clases adineradas y las que venden su fuerza de trabajo o subsisten con mínimos subsidios a la pobreza, ya que las primeras pueden adquirir servicios ecológicos para transitar los efectos de la crisis ecológica reduciendo su vulnerabilidad ante los procesos perniciosos. Un claro ejemplo son las viviendas y barrios construidos como microecosistemas (varios de ellos privados y cerrados) que reducen los impactos ambientales que se multiplican en las ciudades, utilizando tanto objetos de origen natural (como la parquización, forestación e instalación de cuerpos de agua que actúan como depuradores de la polución aérea y la contaminación sonora) como social (como los muros, alambrados, circuitos cerrados de cámaras de vigilancia para separar los habitantes de los barrios privilegiados de los sectores empobrecidos y marginados, resultado de la disgregación socioespacial).

En un cuadro general de descomposición socioambiental y de profundos contrastes, la urbanización capitalista acumula una mayor complejidad en lo que respecta a las problemáticas socioambientales. Cuando más periférica es la posición de la ciudad en el sistema mundial, lo más probable es que más aguda sea la situación crítica. Esto no es un proceso reciente, se trata de una problemática que surge en los albores del capitalismo y en su incipiente desarrollo urbano-industrial. Resulta esclarecedor, en dicho punto, el trabajo de Engels (1845), en el que se detalla que la densificación de las ciudades bajo el capitalismo, a través de un sistema de objetos industriales y urbanos que soportaron, en aquel entonces, el crecimiento demográfico que resultó del movimiento migratorio campo-ciudad (acumulación primitiva). Se trató de un laboratorio para probar la resistencia de las masas urbanas a las peores condiciones de habitabilidad. Esta expansión demográfica y física de la ciudad reproduce una situación socioambiental compleja y problemática conducente a reforzar los antagonismos entre las clases sociales. A mediados del siglo XIX, Engels en pasajes de su obra, utiliza como casos de referencia ciudades industriales de Inglaterra e Irlanda. Respecto a este último país, expone los contrastes socioambientales de Dublín, y concluye que, en realidad, el paisaje urbano que describe es el que se reitera en el resto de las ciudades alcanzadas por

\footnotetext{
5 En China gobierna el «Frente Unido» (dominado por el Partido Comunista Chino) y en Vietnam el «Frente de la Patria de Vietnam» (dominado por el Partido Comunista de Vietnam).
} 
el auge del capitalismo, que se expandirá en el siglo XX en varios países promoviendo la industrialización (Figura 1) y el poblamiento concentrado.

La ciudad misma posee grandes bellezas, y sus barrios aristocráticos han sido construidos mejor y con más gusto que aquellos de cualquier otra ciudad británica. Pero en cambio, los distritos más pobres de Dublín se cuentan entre los más repugnantes y más feos que se puedan ver, ... Los distritos pobres de Dublín son extremadamente extensos y la suciedad, la inhabitabilidad de las casas, el abandono en que se hallan las calles, superan la imaginación, ... La miseria de Dublín no tiene absolutamente ya nada de específica, propia de la ciudad irlandesa, y es por el contrario un rasgo común de todas las grandes ciudades del mundo entero. (Engels, 2009).

Figura 1.«Elevadores a pleno sol». Autor: Benito Quinquela Martín. Obra, concluida en 1945, que refleja el paisaje industrial y portuario en el sur de Buenos Aires y a los trabajadores doblados por la carga y el esfuerzo.

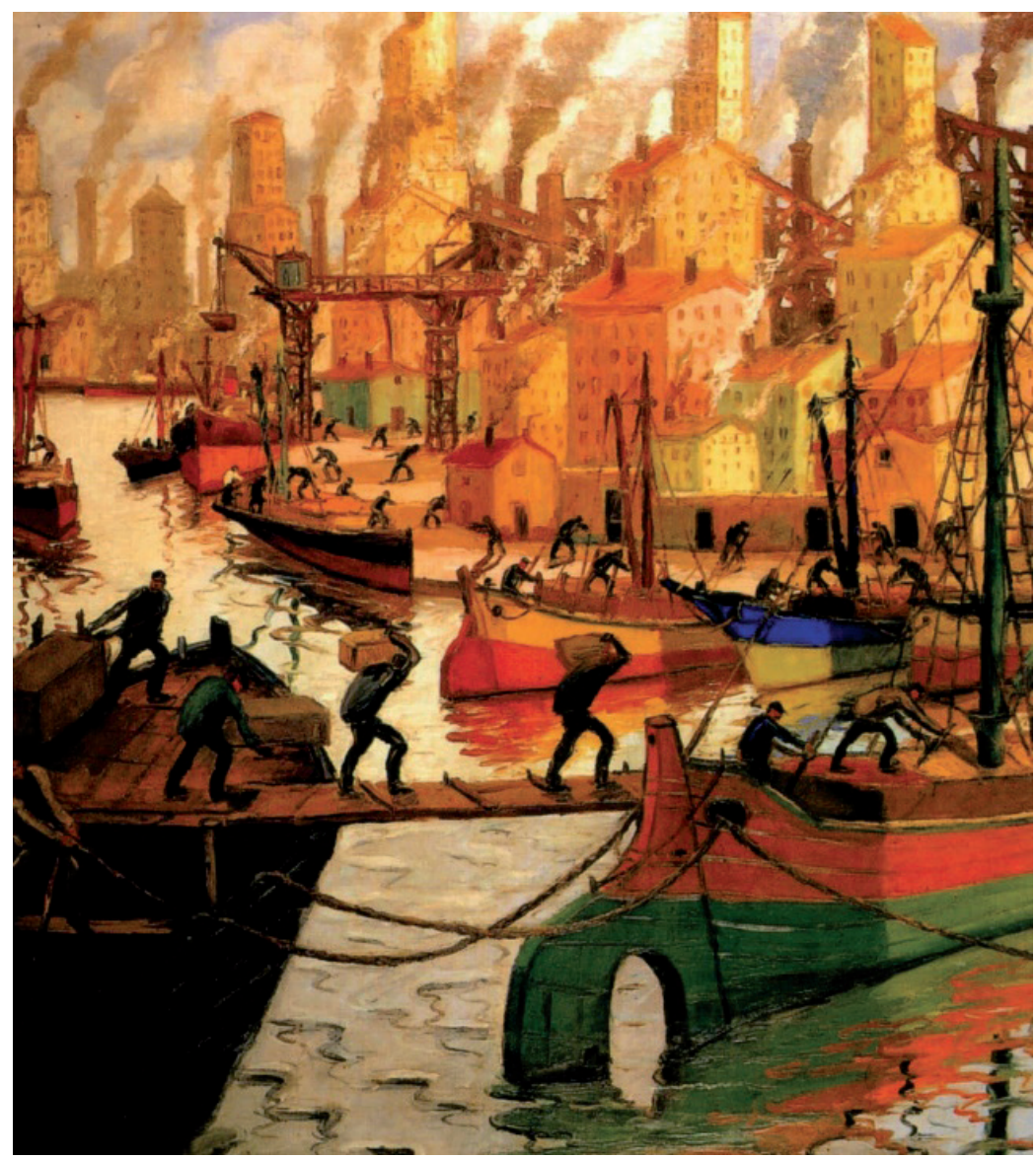

Fuente: Museo Nacional de Bellas Artes, Buenos Aires, Argentina (2019). 
Figura 2. Contaminación atmosférica en Santiago de Chile. Fotografía tomada desde el Cerro San Cristóbal en el año 2018, en el que se puede apreciar el smog fotoquímico.

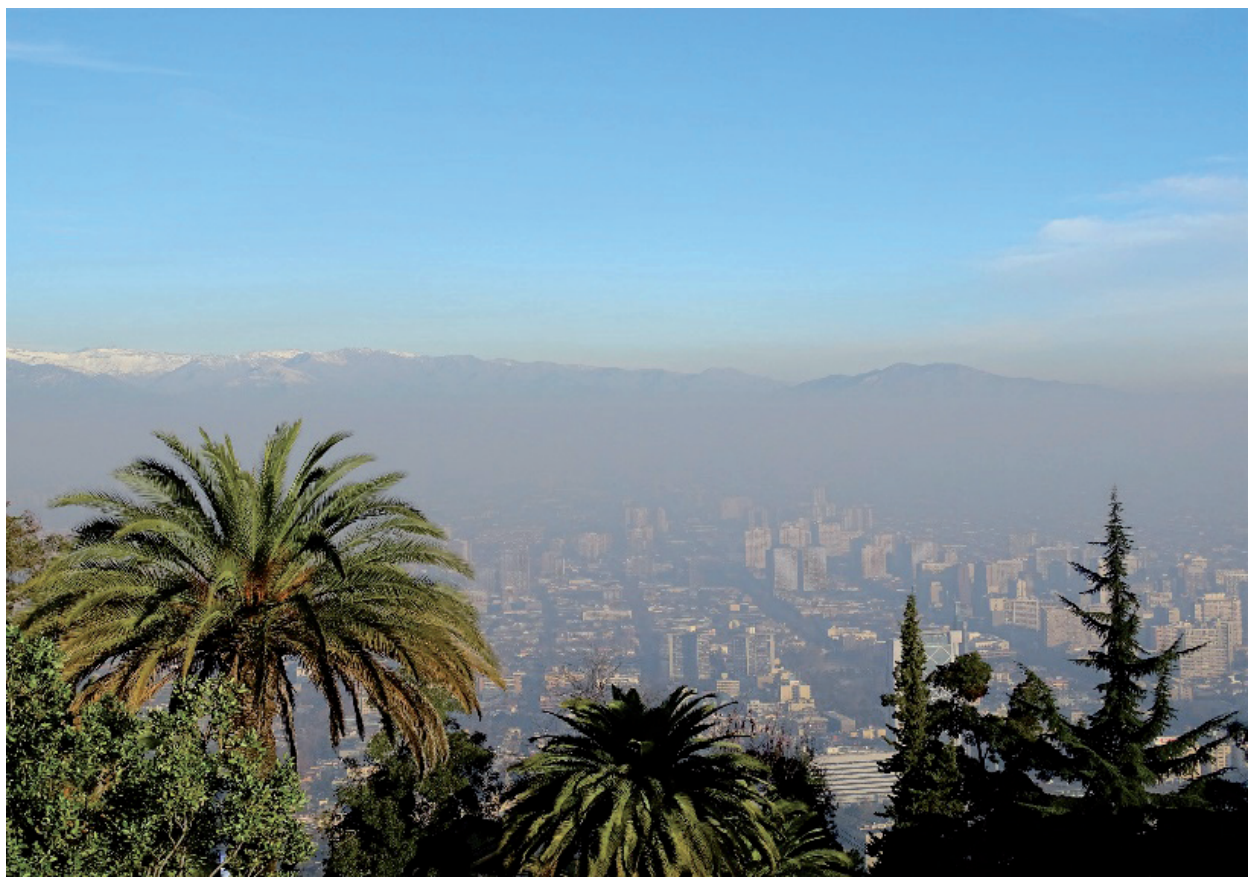

Fuente: archivo personal (2018).

La radiografía que Engels expone en su libro inaugura una ecología política, urbana y crítica que apunta a la urbanización capitalista. Tal descripción persiste en el presente, ya que el paisaje actual y fragmentado en las ciudades es resultado de los antagonismos reproducidos por el mismo modelo socioeconómico que zanja la división de clases sociales también en lo espacial, y agudiza los contrastes entre los $<<$ nichos urbanos $>>$ de las clases altas y los guetos de los sectores populares empobrecidos. Esto acontece en todas las ciudades del mundo, sucede en Yakarta, Lima, Kinshasa, Los Ángeles, Paris, etc. Incluso, hasta alcanzar cierto desarrollo y crecimiento, hay ciudades que han pasado a tener problemáticas socioambientales crónicas transformándose en urbes <<enfermas o padecientes $>>$ que en sus ciclos de vida cotidiana impactan en la salud de todos los habitantes, atravesando las clases sociales (Figura 2). No obstante, los barrios cerrados y privados y los edificios sustentables, orientados a los sectores más solventes, se diseñan con mayor confort ambiental y permiten matizar o absorber parte de los síntomas.

Las ciudades son representadas, en sus diferentes escalas, como centros de población y polución donde se ha producido un cambio radical de las condiciones naturales sobre las que se asientan (Reboratti, 2006), y se asocian a una vida más artificializada. 
Por otro lado, concebido en el imaginario como lugar saludable, lo rural contrasta con lo urbano desde un plano simbólico y material. No obstante, la industrialización del agro, sobre todo desde la Revolución Verde, iniciada en las décadas de 1960 y 1970, ha generado un crecimiento en las ganancias del empresariado rural a costa de un retroceso en las condiciones de vida y trabajo en espacios rurales, lo que ha supuesto un impacto severo en los ecosistemas, de por sí afectados por la simplificación de especies que reduce la biodiversidad. Por ejemplo, el uso de glifosato, y demás agroquímicos, en los campos plantados con soja están asociados a problemas relacionados con la pérdida de fertilidad de los suelos y con la salud humana ${ }^{6}$. La tala indiscriminada es la cara del mismo problema, se destruye la masa forestal y se simplifica la biodiversidad al liquidarse las cadenas tróficas para expandir las fronteras agroganaderas que no están al servicio de las necesidades alimentarias sino de las expectativas del agribusiness de obtener nuevas ganancias, en nuevos territorios, a bajo costos y a corto plazo, ya que los ritmos producción agotan rápidamente los suelos. Otro aspecto ligado a la primarización de la economía y el modelo extractivista, imperante en América Latina, son los impactos de la megaminería y el fracking que se territorializan, generalmente, en sitios relativamente alejados de asentamientos humanos pero que, por la dinámica ambiental, los efectos se distribuyen a gran escala.

\section{Dinámica territorial y análisis multifactorial: causa y consecuencia}

Lo que hipotetizamos, para orientar una propuesta metodológica, es que la experimentación social y corpórea de las fracturas ecosistémicas es una de las formas de vivenciar, padecer e identificar la existencia urbana y rural. Las alergias por la inhalación de componentes tóxicos en el aire, producto de las emisiones industriales, o las enfermedades cancerígenas estimuladas por la exposición a la fumigación con glifosato en los campos sojeros son ejemplos de experimentar fracturas ecosistémicas en el territorio más vital, básico y complejo: el cuerpo humano. El territorio reconfigurado bajo los efectos de impactos ambientales les exige a los organismos vivos y a las comunidades afectadas, el desarrollo de una relación tensional con el ambiente, basada en el temor,

\footnotetext{
6 En este sentido, los postulados de Carrasco reconocen que «los seres humanos no solo somos producto de los genes de la especie, sino de su interacción controlada por el medio ambiente, hecho que hace imperioso buscar nuevos criterios que precedan el uso de los químicos en el territorio, si entendemos que los mismos tienen efectos perniciosos en la salud humana». Pero, además, abre consideraciones sobre «el modelo de base tecnológica de los agronegocios, como el de soberanía alimentaria y sobre la seguridad alimenticia [...]. No solo se ha convertido alimentos en mercancías para los negocios globales -destruyendo suelos y biodiversidad- sino que se comienza a tener evidencia de que esos alimentos transgénicos no son equivalentes en sus propiedades a los silvestres, tratándose de una equivalencia sustancial» (2011). Al ingresar los agroquímicos al organismo, se hace evidente su condición tóxica y el problema socioambiental que se deriva de su uso en la escala geográfica más elemental: el cuerpo humano.
} 
la inseguridad y la defensa. Por tal motivo, es común en ciudades contaminadas por la emisión de gases industriales o de combustión síntomas como la tos alérgica, que es la respuesta del organismo en defensa a diferentes componentes alergénicos presentes en el ambiente, o el uso de mascarillas como objeto utilizado para mitigar los efectos de la polución ambiental en el sistema respiratorio. Un paisaje enfermo es una consecuencia de la contaminación. Frente a esta emergencia ambiental surgen respuestas colectivas, en las últimas décadas se han multiplicado movimientos socioambientales extraterritoriales (con objetivos y luchas por fuera del ámbito de residencia, de identificación y reproducción socioespacial) y territoriales (en el propio lugar de identidad y existencia material).

El estudio de las problemáticas socioambientales se nutre de la multidimensionalidad del territorio. Discutir un enfoque territorial para el abordaje de la conflictividad emergente en torno a lo ambiental, contribuye a explicar cuál es el punto de encuentro entre ambiente y territorio, qué lazos fíliales se construyen en base a la necesidad del espacio apropiado (derecho a la tierra, a la ciudad, a la vivienda digna) y un ambiente sano (derecho a la salud); cómo se pueden quebrar; por qué se asiste a un estadio de rebelión a escala global en relación con la crisis ecológica; por qué cada vez hay más movimientos socioambientales que reivindican el territorio para avanzar en soluciones concretas; por qué los sectores de poder en la economía de mercado y los gobiernos son los imputados por el grado de descomposición socioambientales, entre otros interrogantes.

Desde lo metodológico, el concepto de territorio es entendido relacionalmente como la reunión de la dimensión material, simbólica y vital que lo constituyen, es correcto sostener que en cada una de ellas hay factores que lo componen. En términos generales, se puede decir que hay cuatro factores: ambiental, sociocultural, económico y político. El análisis de estos es lo que permite dar cuenta de la dinámica territorial que es, en términos generales, el proceso por el cual los diversos factores que componen un territorio producen alteraciones en el mismo, de forma que resignifican su contenido material, simbólico y vital, y le otorgan la propiedad de movimiento permanente. Cabe señalar que los cambios pueden ser dados tanto por una transformación en el orden territorial —la instalación de otro modelo, esto es, la «destrucción» de lo anterior para crear algo diferente» - como por la expansión espacial de un orden territorial vigente que está en pleno desarrollo («avance de la frontera» del modelo) o la aceleración en los ritmos de reproducción de un modelo consolidado (acumulación y densificación de los objetos y acciones, significados y representaciones en un determinado espacio). En concordancia con Fernandes (2005), se puede reconocer que los movimientos de las propiedades de los territorios pueden ser agrupados como de «expansión», «flujo», «reflujo», «multidimensionamiento», «creación» y «destrucción», a los que se han adicionado «retracción», como par antagónico de la primera propiedad. 
Los cambios no siempre son en términos acumulativos o constructivos, pueden ser por dispersión, disgregación, retroceso, de un proceso que está en crisis o caducando. Esto último, se da en un marco en el que una fuerza desencadena una crisis que se la suele homologar, en el imaginario, como un vaciamiento del territorio, cualidad que, en la realidad material, es irrealizable, ya que el $<<$ no territorio $>>$ o la desterritorialización como proceso acabado y único no son posibilidades reales. Por ejemplo, el abandono de un modelo industrializador en una región conduce a que la misma adquiera la cualidad de $<<$ cementerio de fábricas $>>$, y se sostenga la idea de un territorio $<<$ vaciado $>>0<<$ arrasado $>>$. Frente a esto, la población local que persiste en el vacío figurado continúa su reproducción socioespacial a través de la aceptación o no de las nuevas condiciones, al probar alternativas económicas, a fin de mostrar resistencia o lucha por restablecer el orden socio-productivo perdido (recuperación de fábricas bajo control obrero, asistencia estatal, cooperativas, nuevos inversores, etc.). Se hace hincapié que lo dinámico no se expresa pasivamente y no es ajeno a lo problemático. En efecto, determinadas transformaciones ocurren en un contexto de tensión y conflictividad en el tiempo y en el espacio, incluso puede presentarse un desplazamiento de los actores que gobiernan la construcción del territorio, sin que implique un cambio de modelo.

Todo estudio enfocado en la dinámica territorial tiene que ser, necesariamente, multifactorial, es decir, que estén presentes las transformaciones en los factores:

i. Ambiental (FAM): cambios introducidos en el medio ambiente —natural o construido - por el accionar de las fuerzas naturales (fenómenos naturales) o por el accionar de las fuerzas sociales. Son las condiciones topográficas, edáficas, climáticas, geológicas, biológicas del territorio. Además, son los entornos edilicios, las infraestructuras, las viviendas, etc. Son los factores bióticos y abióticos, los sistemas de objetos sociales y naturales. Incluye el cuerpo humano. Es la estructura ecosistémica territorial.

ii. Sociocultural (FSC): cambios en las formas en que se establecen las relaciones, representaciones, expresiones y prácticas sociales en un determinado territorio. Incluye el sistema de creencias que otorga significados a los espacios sociabilizados. Este factor expresa el aspecto simbólico-identitario del territorio. Se destaca, en términos de Tuan (1990), tanto lo topofílico (lo afectivo, el sentido de pertenencia, la identidad e inclusión) como lo topofóbico (el miedo y el temor, el rechazo, la discriminación). Forma parte de la superestructura territorial.

iii. Económico (FEC): cambios en los modos de producción, en las actividades, en los ritmos de comercialización, en los flujos financieros e informacionales mundiales, en las infraestructuras y tecnologías que soportan y permiten el desarrollo o crecimiento económico, en el aprovechamiento de los recursos del territorio, en el mercado laboral, entre otros, que dan forma a una estructura económica territorial.

iv. Político (FPO): cambios en el sistema de poder que rigen y definen un territorio, en las fronteras de todas las escalas de análisis geográfico -tanto las formales (institucionales) como las informales-, en los roles y relaciones del sector público y privado: connivencia, 
asociatividad, confrontación, disputa, como así también hacia el interior de ambos (pugnas entre sectores empresariales, cambios de signo político en los gobiernos, etc.). Se destaca el sistema de normas jurídicas, de hecho, o establecidas en forma independiente de los poderes institucionales. Este factor, junto al sociocultural, constituye la superestructura territorial.

En todo proceso de transformación territorial hay una causa y un efecto. Por lo general, hay un factor fuerte (FF) en el origen de la fuerza que ejerce funciones trasformadoras. Esto es, un factor que explica más que otros las motivaciones de los cambios acontecidos o proyectados. Por ejemplo, la abrupta suba registrada en el precio de la soja en la Chicago Board of Tradeen en el primer decenio del siglo XXI ${ }^{7}$ estimuló el avance de la frontera sojera en todos los territorios aptos para su cultivo. En este caso, el FF en el origen de las transformaciones radicales en las regiones afectadas a la plantación de la soja es un FEC. Repasemos el hecho de que entre los diez principales productores mundiales se encuentran cinco países sudamericanos: Brasil (segundo productor mundial), Argentina (tercero), Paraguay (sexto), Bolivia (octavo) y Uruguay (décimo). En ellos, el cultivo de la soja está aparejado con una serie de problemáticas socioambientales y territoriales. Las consecuencias se derivan de los paquetes tecnológicos que se implementan para mejorar el rendimiento de los cultivos. Estos se basan en el uso semillas transgénicas, fertilizantes fosfatados y nitrogenados, y biocidas (herbicidas como el glifosato, insecticidas como el endolsulfán y fungicidas), todos ofertados por los monopolios multinacionales del agribusiness y la industria química (Monsanto, Cargill).

Los impactos socioambientales han sido devastadores en la salud humana y en los ecosistemas intervenidos por el monocultivo de la soja transgénica, reduciendo la fertilidad del suelo al eliminar los organismos que forman la materia orgánica, contaminando las napas freáticas y el aire por la fumigación aérea, etc. El origen (la causa) tiene como FF el FEC — la expansión de un cultivo cotizado en el mercado mundial - y las consecuencias (el efecto) más en lo ambiental. No obstante, todos los factores participan como causa y consecuencias. Para el ejemplo mencionado, como causa, en el FAM se puede mencionar las condiciones edáficas de los suelos de las pampas húmedas argentinas, uruguayas y brasileñas; de los montes chaqueños paraguayos y argentinos; de los llanos occidentales bolivianos; del pantanal y bosque atlántico brasileño; y de la selva amazónica, son aptos para el cultivo de la soja a través del paquete biotecnológico. Como FPO, cabe destacar la permeabilidad de los gobiernos a introducir medidas que favorezcan a los agribusiness en desmedro de la calidad de vida de la población y del medio ambiente, fomentando políticas contribuyentes a promover fracturas ecosistémicas, por ejemplo, autorizando el uso de componentes químicos prohibidos en otros países. Y como FSC, es pertinente destacar que los países sudamericanos involucrados

\footnotetext{
7 El precio de la soja pasó de 421 US\$ la tonelada en diciembre de 2001 a un récord histórico de 1754 US\$ en abril de 2012, lo que supuso una triplicación del valor en poco más de una década.
} 
en la expansión del modelo extractivista sojero están identificados en sus raíces históricas con la ruralidad (identidad promovida por el modelo agroexportador desde fines del siglo XIX), por lo tanto, la expansión del suelo cultivable es apreciada, en sectores de la población (no necesariamente rural), como iniciativas que contribuyen al reforzamiento de la cultura productiva.

Por el lado de las consecuencias, además del FF que es el FAM están los demás relacionados. Las consecuencias en el FEC se manifiestan en la dependencia de las economías nacionales de la producción y cotización del cultivo, incluso en la expectativa de los gobiernos de poder captar esa riqueza, a través de cargas impositivas, que le posibiliten iniciar medidas de desendeudamiento externo, lo que incita aún más a promover políticas de estímulo para el avance de la frontera sojera en nuevos territorios. En el FPO una de las expresiones más claras es cómo los terratenientes, los agribusiness y las multinacionales industriales ligadas al agro influyen en los gobiernos de la región, e intervienen en procesos electorales mediante aportes a campañas proselitistas, en las votaciones en los parlamentos de leyes que los beneficien, en el uso de las fuerzas represivas del estado ante amenazas a sus intereses, etc. En el FSC el rasgo que más se reitera es el despojo de miles de campesinos de sus tierras, de sus medios de existencia y la pérdida de sus saberes, desposesión efectuada la mayoría de las veces con el uso del aparato represivo estatal y/o paraempresarial.

Con el ejemplo anterior, expuesto a grandes rasgos, pero que refleja una situación conocida y repetida, se da cuenta de la perspectiva de la propuesta conceptual y metodológica, entendiendo que el territorio es movimiento y multifactorial, y que la problemática socioambiental es una expresión de tales cualidades.

\section{LA FUERZA TDR Y LOS TRAUMAS TERRITORIALES}

Expresado en forma general, la presente propuesta para estudiar la dinámica del territorio y aplicarla a las problemáticas socioambiental se apoya en la detección de cambios profundos que acontecen en los diferentes factores. Esto último es denominado «punto de inflexión» (PI) en la construcción territorial; es decir, el momento o período (dimensión temporal) en el que se ocasiona una transformación en un determinado lugar (dimensión espacial) de tal forma que es dificultoso o imposible, según el caso, retornar al estado previo. Este es el momento en que se produce lo que Raffestin (2019) denomina proceso de <<territorialización-desterritorialización-reterritorialización>> (TDR). Desde un ángulo sistémico, se dice que se trata de una fuerza que ingresa al territorio y modifica las relaciones socioespaciales, los objetos que lo componen y los significados que expresan. La fuerza TDR no implica por sí misma la eliminación completa de un orden y/o modelo territorial y la instauración de otro, sino formas convivientes producto de las resistencias, resiliencias o rugosidades (Santos, 1997) 
que se presentan en el espacio social y natural. No obstante, cierta radicalización en las transformaciones puede desencadenar un cambio rotundo en todos los factores, a tal punto, que no deje huellas nítidas de la historia previa o lo que subsista sea una expresión de lo que ha sido destruido. Un caso que expresa con notoriedad este tipo de transformaciones territoriales radicales son las guerras, en las cuales se instala una dinámica que consiste en cambios abruptos y deshumanizantes al tratarse de un PI que destruye vidas, pueblos, culturas, ecosistemas, y reduce las infraestructuras a escombros.

A todo conflicto socioambiental le antecede un PI en la construcción territorial, o su posibilidad. En la detección de los PI es fundamental visibilizar qué actores intervienen estimulando la fuerza TDR, si son los mismos que hegemonizaban en el estado previo, y que suponen una ruptura con una posición conservadora o de contención, o si son otros que han desplazado a los que estaban ejerciendo el poder en el territorio. Un ejemplo que clarifica la relación entre los actores sociales y la construcción territorial son los incendios en la Amazonia. Estos son PI que actúan como método de expansión de la frontera agroganadera a través de la destrucción del ecosistema selvático y el desplazamiento de las sociedades que allí habitan. Se trata de una fuerza TDR que desplaza al actor (comunidades indígenas) que ocupaba el territorio y le imprimía sus lógicas a la construcción territorial. Otro ejemplo, en el cual es el mismo actor el que promueve una fuerza TDR, son los casos de desafectación de áreas protegidas para el desarrollo de emprendimientos mineros, ampliación de trazas urbanas, instalaciones portuarias, infraestructura y servicios turísticos, entre otras. En estos ejemplos, es el mismo actor - las diferentes escalas político-administrativas del Estado — quien genera la fuerza TDR, a fin de liberar territorios preservados por el mismo, bajo una perspectiva ambiental, para la instalación de empresas públicas o privadas que desarticulan la relación sociedad-naturaleza preestablecida. Todos estos casos pueden analizarse en diferentes escalas territoriales (análisis multiescalar), ya que cabe la posibilidad de que la fuerza TDR se manifieste en cada una de ellas (por ejemplo, el cambio climático) o lo haga en algunas (casos regionales o nacionales que contienen las escalas inferiores) o una sola (casos locales o barriales).

El método trabajado (Figura 3) propone estudiar la dinámica territorial en dos etapas: la primera consiste en detectar el FF del PI y las características (motivos, cualidades, alcances) de la fuerza TDR. La segunda etapa consiste en establecer cómo el FF que compone el PI se disemina e interactúa en los demás factores y cuáles son las consecuencias de las transformaciones que dan cuenta de la dinámica de la unidad territorial estudiada. A fin de resumir lo planteado en las dos etapas, es adecuado decir que el solo análisis del FF en el PI conduce a un estudio incompleto e inacabado de la dinámica territorial. Por tal motivo, el abordaje debe ser multifactorial y dinámico ya que toda fuerza TDR tiende a consolidar una configuración territorial hasta que esté nuevamente sujeta a otra presión iniciada por una nueva fuerza TDR. 
Figura 3. Esquema del método de análisis de la dinámica territorial multifactorial

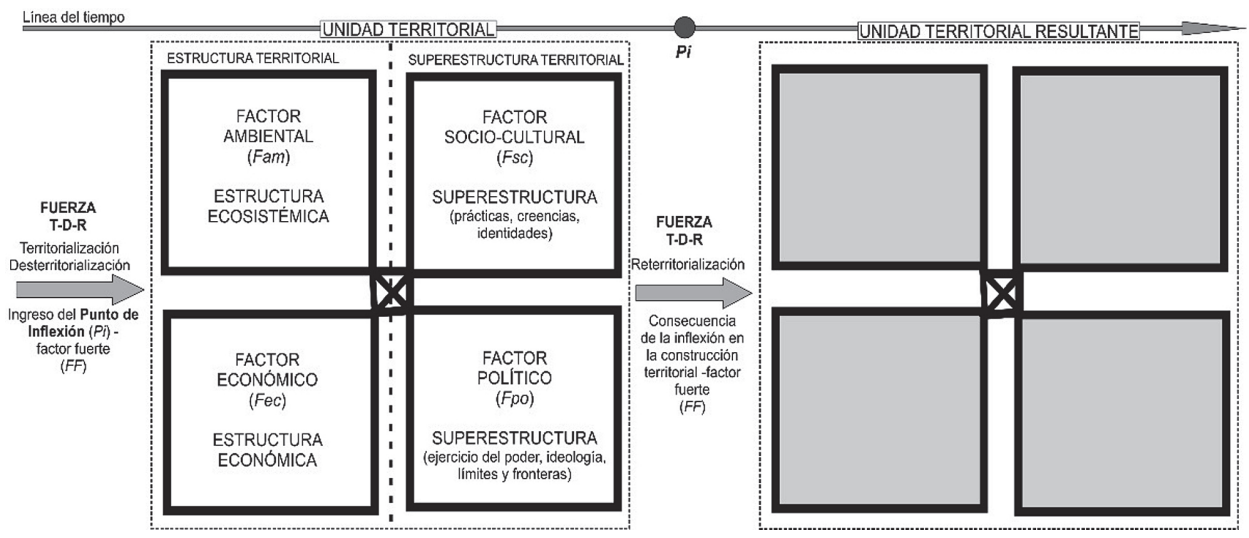

Un punto para incorporar es que cuando una fuerza TDR tiene una incidencia radical en lo que se refiere a transformaciones territoriales que tienen claras connotaciones destructivas, inhumanas, genocidas, ecocidas, el PI se homologa a lo que puede definirse como $<<$ trauma territorial $>>$. Este es un impacto acontecido sobre el espacio apropiado y significado que deja una marca, se trata de una herida que acompaña la configuración pasada, presente y futura. Se trata del horror, el sufrimiento, la aniquilación, como resultado de un accionar social o un evento natural de dimensiones catastróficas. Por ejemplo, en Argentina, Chile y Uruguay, los centros clandestinos de detención, tortura y desaparición forzosa de personas de las últimas dictaduras cívicomilitares de las décadas de 1970 y 1980 son territorios atravesados por los crímenes de lesa humanidad que se cometieron en los mismos, a tal punto que han sido relevados, seńalizados con placas recordatorias y, algunos, convertidos en museos de la memoria y de los derechos humanos. La necesidad de mantener activa la memoria del horror es lo que expresa, en este caso, lo traumático; convivir con la historia es, precisamente, no olvidar para que nunca más vuelva a ocurrir.

También, un evento natural de dimensiones catastróficas puede provocar un trauma territorial. Por ejemplo, la erupción del Volcán Vesubio destruyó por completo en el siglo I las antiguas Pompeya, Herculano y Oplontis, ciudades del Antiguo Imperio Romano, y que las enterraron en cenizas por catorce siglos hasta que fueron descubiertas. La devastación quedó adherida al paisaje en forma de moldes de yeso con el que se fosilizaron las víctimas. En la actualidad, el conjunto arqueológico es un museo al aire libre, declarado como Patrimonio por la Humanidad por la Unesco en 1997 y transformado en uno de los atractivos turísticos más visitados de Italia. Incluso el hecho de que pueda mercantilizarse el antiguo territorio que ocupaban las ciudades y poblados al pie del Vesubio, para satisfacer la curiosidad del turista, radica en que se trata de un trauma territorial del que ha quedado un testimonio físico y material. 
Para reforzar esta propuesta conceptual es prudente tomar a modo de ejemplo dos casos mundialmente conocidos, que comparten un mismo contexto histórico y conflicto: Auschwitz e Hiroshima y Nagasaki. En ambos casos, la misma toponimia nos conduce inmediatamente a reconocer dos hechos trágicos. El primero, se trata de la referencia territorial del Holocausto étnico, político y religioso que cometió el régimen de la Alemania Nazi durante la Segunda Guerra Mundial en los campos de concentración, siendo el complejo de Auschwitz-Birkenau (que comprendía varios campos entre 1940 y 1945), ubicado en Oświęcim, Polonia (Figura 4), el más significativo por su tamaño, organización y número de víctimas. El segundo, se trata de las dos ciudades japonesas en las que la Fuerza Aérea de los Estados Unidos lanzó los únicos ataques nucleares de la historia: Hiroshima el 6 de agosto de 1945 (Figura 5) y Nagasaki tres días después. El Imperio del Japón era el único país del Eje que en agosto de 1945 no se había rendido a los Aliados. Para que el emperador capitulara, en los términos de la Declaración de Potsdam, se bombardearon ambas ciudades. Estas ciudades presentan un trauma territorial, una expresión material y simbólica del daño extremo, por tal motivo, se fundan espacios de la memoria para reivindicar la paz, no renunciando a relatar el horror de la guerra y el régimen nazi. En estos lugares, con sus monumentos, cenotafios y museos, la identidad está atravesada por esa experiencia y su contribución a la concientización.

\section{Conflictividad socioambiental como conflicto socioterritorial: ejemplos latinoamericanos}

En este artículo, se presenta la crisis y conflictividad socioambiental actual como resultado de las contradicciones del sistema de producción capitalista, anidadas en la necesidad imperiosa de expandir la tasa de acumulación y acelerar la tasa de rotación, lo cual consume espacios vitales y la vida misma. Por tal motivo, se puede considerar la validez de la segunda contradicción del capitalismo desarrollada por O'Connor (1998). En términos generales, esta contradicción resulta de la apropiación y el uso abusivo del capitalismo de los cuerpos y la psique de los trabajadores, del espacio producido socialmente y de la naturaleza o medio ambiente externo. A diferencia de la primera contradicción que proviene desde la demanda, la segunda se genera al afectar los costos (O’Connor, 1992).

Dentro de este encuadre conceptual y metodológico, se propone entender las problemáticas socioambientales como procesos que dan cuenta del dinamismo territorial ya que se tratan de respuestas ecosistémicas a las presiones introducidas por determinados actores sociales y por fuerzas naturales que impactan en las infraestructuras, objetos y cuerpos expuestos. Esto impacta en el entramado social y su entorno vital, a los que habitan y construyen su existencia dentro de la escala espacial afectada por un fenómeno socioambiental que desarticula las relaciones socioambientales preestablecidas. 
Figura 4. Museo Estatal de Auschwitz-Birkenau. Antigua entrada al mayor campo de concentración de la Alemania nazi, donde se inmortaliza la frase «El trabajo nos hace libre».

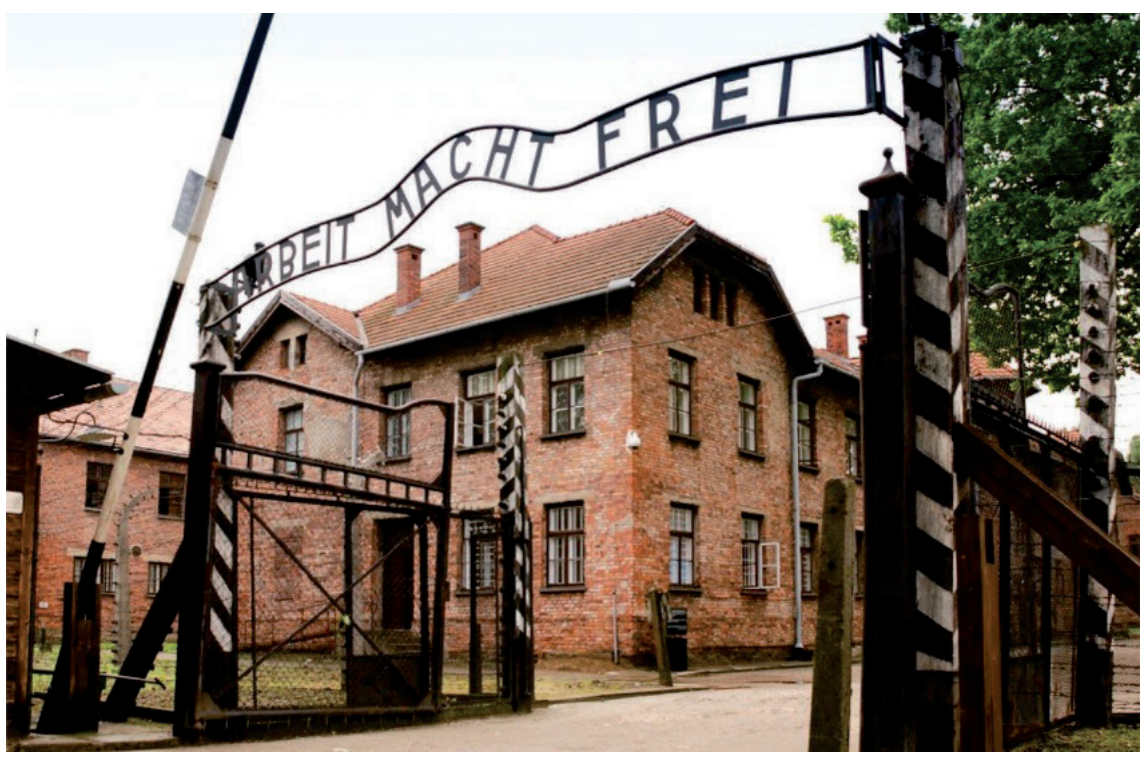

Fuente: Museo Estatal de Auschwitz-Birkenau (Polonia).

Figura 5. Conmemoración de la Paz de Hiroshima (cúpula Genbaku). Se trata de la edificación más próxima al hipocentro de la bomba atómica que resistió al impacto de la explosión.

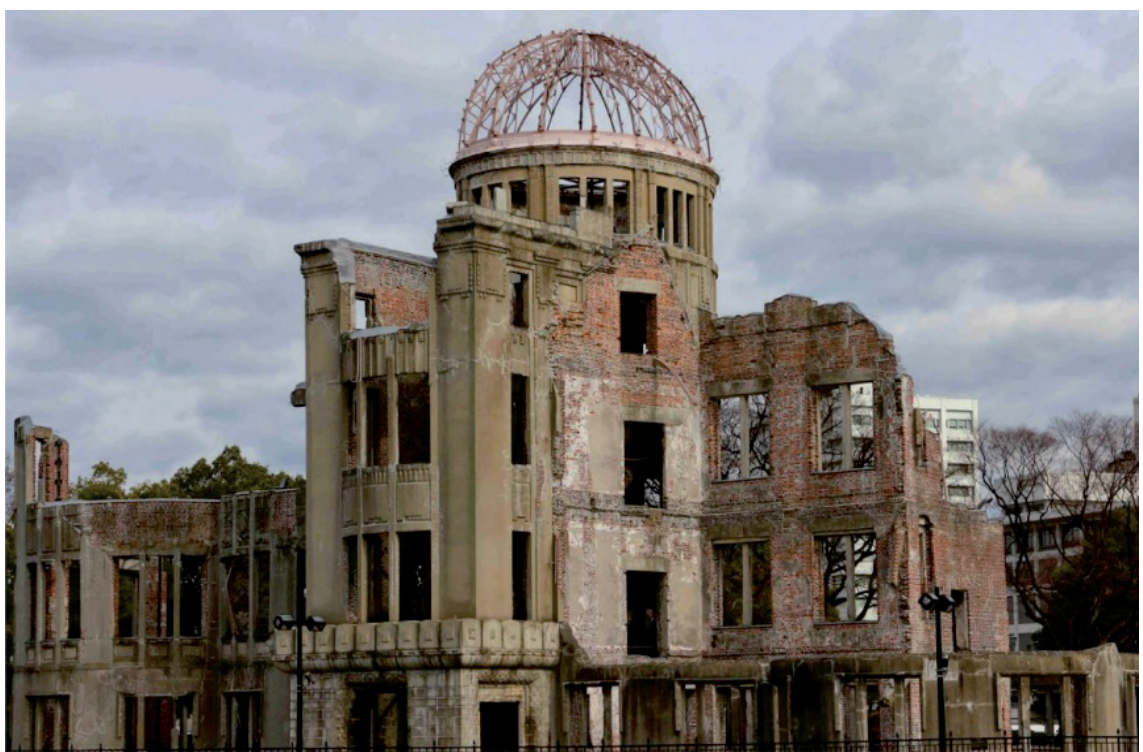

Fuente: Documenting Ian Blog. 
Alcanzada cierta intensidad o perdurabilidad el problema socioambiental se homologa como fuerza TDR. Cuando los desajustes se multiplican y acontecen en todos los factores del territorio, y provocan dańos irreparables al medio ambiente y a las sociedades humanas, se manifiesta lo que Leff (2004) expone como «el desquiciamiento del mundo al que conduce la cosificación del ser y la sobreexplotación de la naturaleza».

La propagación de los problemas socioambientales refleja la situación de crisis socioambiental a escala planetaria que no solo fija los límites de la racionalidad económica imperante, sino también la crisis del Estado capitalista, de sus políticas públicas destinadas al manejo ambiental que colisionan con las contradicciones y necesidades expansivas propias del régimen social que reproduce. Esto promueve una «crisis de legitimidad» (Wagner, 2010) que socava las instancias de representación formales de la administración pública, de la normativa y de los sistemas jurídicos, en este caso, en lo que se refiere a la cuestión socioambiental. Es importante recalcar el hecho de que, durante la década de 1990, en los países de América Latina, se consolidaron diferentes carteras ministeriales abocadas al medio ambiente, con un presupuesto asignado, recursos humanos, herramientas ejecutivas, sistemas de normas y penas, etc. Esto fue promovido en las resoluciones de la Cumbre de la Tierra de Río de Janeiro (1992). No obstante, esto no significó un avance en la materia y, menos aún, en la necesidad de reforzar una política preventiva para mitigar los efectos de la crisis ecológica de la región.

Los gestores del territorio y el medio ambiente más efectivos han sido, por lo general, movimientos sociales conformados y organizados defensivamente contra la acción de privados, empresas y/o agencias de gobierno que promueven fracturas ecosistémicas. La emergencia de estos últimos, y su crecimiento en las últimas décadas, exponen el fracaso de los diferentes gobiernos de la región en la temática, ya que los hechos demuestran la agudización de la descomposición socioambiental en América Latina. Cuando el problema socioambiental deriva en un choque entre diferentes actores, los que lo desconocen y los que lo denuncian, lo que surge es un conflicto socioambiental. Un problema ambiental puede ser, en cierto nivel, socialmente abstracto, puede existir sin que haya una conciencia que lo registre como tal, incluso puede pasar tiempo sin que sea detectado. En cambio, el conflicto es un hecho concreto, consciente, de tensión y confrontación, en el que, a primera vista, las instancias de consenso están debilitadas y fortalecidas las de disenso. Los problemas socioambientales que caracterizan a América Latina y al resto del mundo son expuestos, difundidos y definidos por obra del disenso y de la disputa en torno al territorio, su identidad y materialidad. Los movimientos socioambientales ${ }^{8}$ enuncian nuevos

\footnotetext{
8 Sobre estos movimientos se recomienda los trabajos de Porto Goncalves, 2005; Ascerald, 2010; Svampa, 2012; entre otros.
} 
derechos y libertades democráticas que le exigen a los organismos internacionales, a los Estados, a las cortes de justicia y a las grandes corporaciones que tienen incidencia mundial. El conflicto socioambiental es inevitable, pero no como un hecho negativo, sino como una respuesta social confrontativa de actores que antagonizan con sujetos de poder, con el fin de presionar y reencauzar soluciones a problemáticas socioambientales que desmejoran la calidad de vida humana y de las demás especies. En este caso, la pasividad y tolerancia sería el dato negativo, porque al dejar la iniciativa a los actores de poder o aceptar el orden instalado, lo que se promueve es la acumulación de más poder e impunidad para ejercerlo?.

Uno de los casos actuales que demuestra la efectividad de los movimientos y el conflicto aconteció en la Argentina, en el cual la movilización popular impidió que, en la provincia de Mendoza, el parlamento provincial modificara, en diciembre de 2019, la Ley 7722 que prohíbe la utilización de materiales contaminantes (cianuro, mercurio, ácido sulfúrico, etcétera) en la actividad minera. Los intereses del lobby minero presionaron para que las actividades de expansión del sector se desarrollasen bajo las necesidades operativas del empresariado a costa de la salud y el medio ambiente. Los límites a un potencial despliegue de una fuerza TDR de alto impacto ambiental no los puso el régimen de gobierno (ya que el Senado, bajo el auspicio del ejecutivo provincial, promulgó la modificatoria), sino la organización y unidad del pueblo, los movimientos socioambientales y su lucha en las calles. Luego de intensas jornadas durante diciembre de 2019 y enero de 2020, los sectores sociales movilizados y solidarizados en todo el país, con epicentro en la provincia de Mendoza, lograron que se desestimara la reforma a la norma.

Los problemas y conflictos socioambientales son una muestra cabal de lo dinámicos que son los territorios, de las interconexiones entre los factores que lo componen, de lo conflictivo que suelen ser las transformaciones y de la multiplicidad de interpretaciones de estas. Sobre esto último, determinados impactos ambientales, para quienes hegemonizan la construcción del territorio, son asumidos como $<<$ daños colaterales $>>$ $\mathrm{o}<<$ externalidades negativas $>>$ — un aspecto que lo liga a la contabilidad — del desarrollo, y para otros, los que padecen las consecuencias por su grado de vulnerabilidad y exposición, se trata de <<daños vitales $>$. Esto se puede relevar y corroborar en los discursos periodísticos, ya que mientras las corporaciones mediáticas, que ejercen como lobistas de empresas acusadas por sus impactos ambientales, difundieron las contraargumentaciones para defender intereses propios y ajenos, los medios de información que fundan los colectivos sociales críticos contra el saqueo de recursos naturales y la expoliación ambiental, además de demostrar los impactos de una intervención

\footnotetext{
9 Se sugiere la lectura de Sabatini (1994) y Castillo (2013) para profundizar el análisis crítico de los conflictos socioambientales.
} 
en el territorio, agitaron consignas movilizantes. Incluso, en ambos discursos, puede utilizarse en forma auxiliar el discurso científico, ya que cada uno de los intereses en disputa están representados por modelos de ciencia diferentes.

Otro caso que refleja la importancia del cruce discursivo es lo que ocurrió en Chile con el proyecto HidroAysén, respaldado y aprobado por el gobierno de Sebastián Piñera ${ }^{10}$ en mayo de 2011. Este contemplaba la construcción de cinco represas en la Región de Aysén que inundarían 5900 hectáreas y que generarían, según los cálculos publicados por la empresa, una energía media anual de $18430 \mathrm{GWh}^{11}$, aproximadamente el $20 \%$ de la demanda eléctrica del Sistema Interconectado Nacional. Con una inversión estimada en 3200 millones de US\$, se trataba de un emprendimiento financiado por capitales extranjeros, a través de la empresa ENDESA ${ }^{12}$ (propiedad mayoritaria de la multinacional italiana $\mathrm{ENEL}^{13}$ ), y capitales nacionales mediante la participación de Colbún SA, controlada por el Grupo Matte. Diferentes organizaciones ambientales y estudios académicos estimaron, a partir de diferentes estudios, que la construcción y puesta en operación de todo el proyecto impactaría en 91 diferentes áreas protegidas (parques nacionales, reservas nacionales, áreas protegidas privadas) ${ }^{14}$. Además, su concreción, afectaba a varias comunidades mapuches de La Araucanía, ya que las mismas tenían que ceder parte de su territorio y recursos para la construcción de las redes de alta tensión. Esto desencadenó una serie de manifestaciones en todo el país y en otros lugares del mundo en oposición a la construcción de las cinco represas por el daño socioambiental que generarían. Transformado el proyecto en un campo de disputa, los medios de comunicación comenzaron a difundir las diferentes posiciones en torno a HidroAysén. En algunos casos, la misma empresa pagaba publicidad pública para difundir los beneficios para el desarrollo nacional del emprendimiento (Figura 6) y contaba con medios de comunicación aliados. Mientras que los manifestantes, las comunidades mapuches afectadas y los movimientos socioambientales desplegaban su campaña y consignas en las calles (Figura 7) las voces opositoras eran reproducidas en medios de comunicación alternativos, en la prensa militante y en publicaciones de difusión científica.

\footnotetext{
${ }^{10}$ Sebastián Piñera cumplió su primer mandato presidencial entre los años 2010-2014 encabezando las listas de la alianza entre la Unión Democrática Independiente y el partido conservador-liberal Renovación Nacional, espacio político del cual provenía el presidente electo.

${ }^{11}$ Gigavatio-hora.

${ }^{12}$ ENDESA es el acrónimo de Empresa Nacional de Electricidad Sociedad Anónima.

${ }^{13}$ ENEL es el acrónimo de Ente Nazionale per L’energia Elettrica.

${ }^{14}$ Para más detalles sobre informes y crónicas de sucesos en torno al conflicto de HidroAysén se recomienda la lectura del trabajo de Sonia Reyes Herrera y Juan Carlos Rodríguez Torrent (2015), titulado: «Proyecto Hidroaysén: capitalismo extractivista, regulación estatal y acción colectiva en la Patagonia».
} 
Figura 6. Publicidad de HidroAysén en el metro de Santiago de Chile (2011). En la misma se puede leer el texto «El agua es nuestro recurso ¿̨or qué depender de otros?».

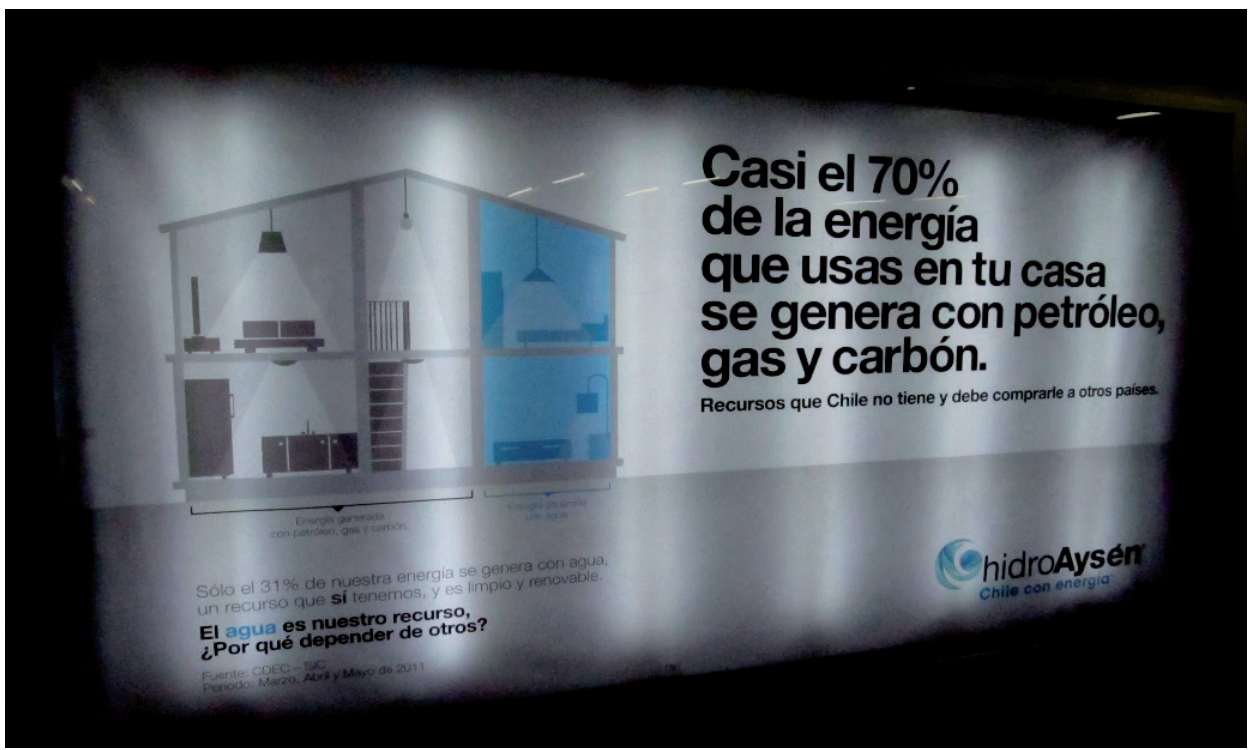

Fuente: Nodal. Noticias de América Latina y el Caribe.

Figura 7. Movilización en Curicó (Región del Maule) en oposición al proyecto de las hidroeléctricas. La bandera de arrastre lleva la consigna «HidroAysen Miente».

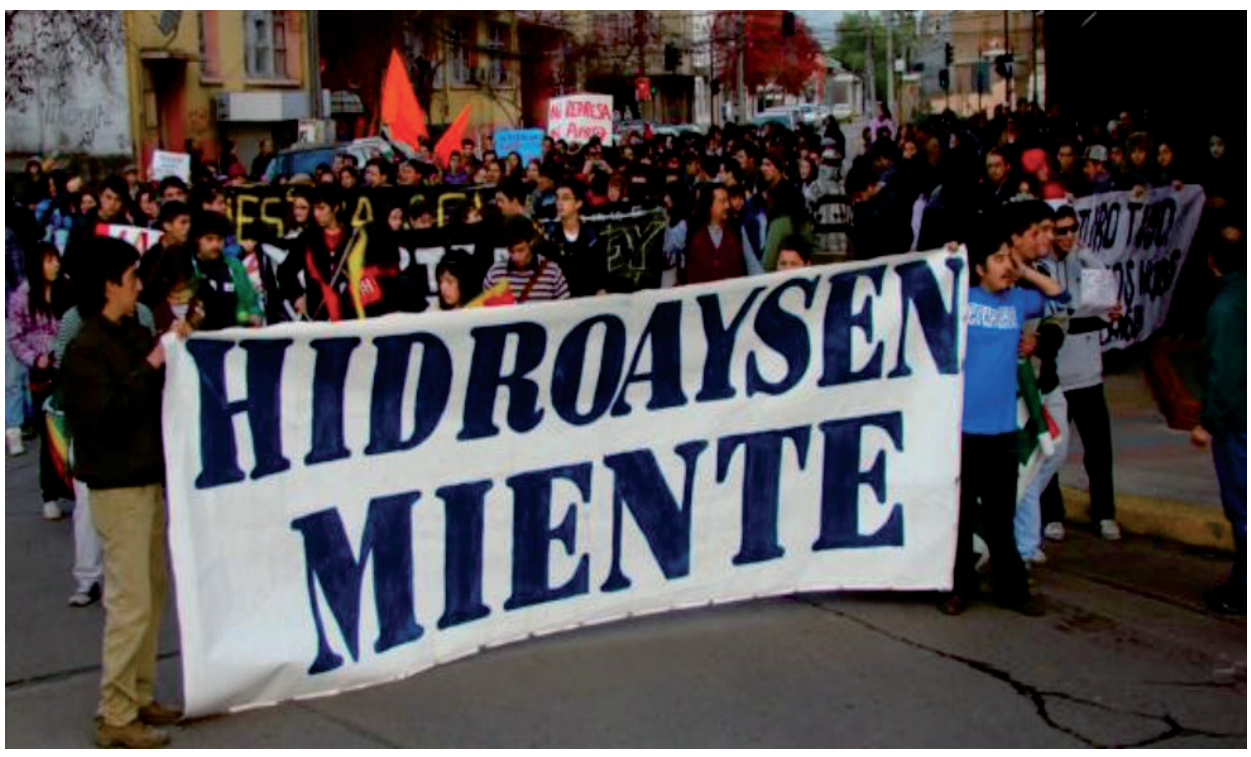

Fuente: Warko (Creative Commons). 
Finalmente, luego de varias presentaciones judiciales en contra de HidroAysén, la Tercera Sala de la Suprema Corte, en abril de 2012, desestimó las denuncias y autorizó el proyecto (Suprema Corte de Chile, 2012), incluso bajo la sospecha de conflicto de intereses que involucraba a uno de los magistrados que tenía acciones en una de las empresas operadoras en el mercado eléctrico (BBC Mundo, 2012). No obstante, continuó la campaña en contra del proyecto, el cual logró la movilización y la solidaridad internacional hasta que el Comité de Ministros en funciones en junio de 2014 (en la presidencia de Michelle Bachelet ${ }^{15}$ ) resolviera revocar la Resolución de Calificación Ambiental del proyecto HidroAysén debido a la presión social.

En la amplia mayoría de los conflictos socioambientales que se multiplican América Latina y en el mundo, lo que se puede corroborar es que, en algún punto o desde el inicio, estos se relacionan con las pugnas por el espacio apropiado y significado, incluso puede darse el caso de que se asumen como luchas territoriales. Esta conflictividad termina refiriendo a una disputa por lo territorial, y, en esa instancia, los discursos se transforman, también, en territoriales ${ }^{16}$. La pugna en torno a HidroAysen fue una disputa por el territorio. Precisamente, el giro ecoterritorial al que alude Svampa $(2012,2017)$ desde una mirada latinoamericanista, presenta la virtud de demostrar que lo ambiental y lo territorial están amalgamados, y que se vuelven indiferenciables. El concepto propuesto por la autora es una consecuencia de «la dinámica de las luchas socioambientales en América Latina» que asentó la base de «la emergencia de un lenguaje común que da cuenta del cruce innovador entre matriz indígena-comunitaria, defensa del territorio y discurso ambientalista» (Svampa, 2012).

\section{Apuntes didÁcticos}

Para cerrar estas notas se expone, sintéticamente, una propuesta de presentación y organización didáctica para abordar los conflictos socioambientales desde un enfoque territorial. Esto se realiza con la finalidad de proponer ejercicios que, en términos de Freire (2000), promuevan la "curiosidad crítica» en diferentes niveles educativos en los que se imparte la geografía y demás ciencias sociales o naturales que abordan la temática. En coincidencia con el autor, una formación educativa, en todos sus niveles, «puede estar tanto al servicio de la decisión, de la transformación del mundo, de la inserción crítica

\footnotetext{
15 Esto se resolvió en la segunda presidencia de Michelle Bachelet (2014-2018), quien había sido electa como candidata de la coalición centroizquierdista «Nueva Mayoría».

${ }^{16}$ Para Hernández y Furlan (2016), el discurso territorial se trata del «acto oral, escrito y/o no verbal que un actor social utiliza para comunicar o exponer los motivos y argumentos de sus particulares acciones de territorialización o para cuestionar las que otros han efectuado en el mismo, con el objetivo de imponer, justificar, convencer o persuadir al interlocutor de que tales acciones son correctas-incorrectas, sinceras-hipócritas, beneficiosas-perjudiciales, para el territorio, según se las esté ejecutando o cuestionando [...]. Por lo tanto, es este uso específico que se hace del discurso, y no su tópico general, lo que lleva a calificarlo de territorial».
} 
en él, como al servicio de la inmovilización, de la persistencia de las estructuras injustas, de la acomodación de los seres humanos a una realidad considerada intocable». La idea de este segmento final del artículo es promover la «reescritura del mundo» (Freire, 2000) a través del estudio de los conflictos socioambientales y su base territorial.

En la primera etapa del ejercicio propuesto, es conveniente seleccionar un caso en el que el alumnado cuente con un nutrido acceso a la información. Es necesario garantizarse que el material que puedan recabar lo obtengan de diversas fuentes, con la finalidad de que reúnan las distintas posiciones ante el mismo conflicto y de las «lecturas del mundo» (Freire, 2000) que hacen los actores involucrados y confrontados. Los métodos de recolección pueden variar según la proximidad respecto al objeto de estudio y los recursos disponibles, se destaca la posibilidad de efectuar observaciones participantes, entrevistas a informantes clave y/o a los actores demandantes y demandados, encuestas, etc. Ocupa un lugar esencial, por la influencia que ejerce en las representaciones socioespaciales y socioambientales, la recopilación periodística, siempre identificando la línea editorial para evitar incurrir en el error de consentir la objetividad y neutralidad plena de la información propagada, sobre todo «en el modo actual en que se organiza el mundo de los medios de comunicación» (San Martín, 2008). El periodismo no es un espejo de la realidad, sino que elabora una imagen del mundo con base en determinados intereses a los que responde y la difunde para instalarla en la agenda pública. Desde un ángulo crítico, los alumnos tienen que relevar el «cómo» aborda los medios de comunicación los hechos que involucran a un conflicto socioambiental y detectar el encuadre territorial, y no traducir el acontecimiento periodístico como un fragmento de la realidad socioespacial inobjetable.

Es necesario recabar, en tiempos de inmediatez en la difusión de la información y la opinión, los materiales expuestos y discutidos en redes sociales y foros en línea que aborden el conflicto. Estos ocupan un lugar importante en la mediación entre el «ser», su expresión y sentir sobre su entorno y el espacio significado. Con base en lo expuesto por Verón (1981), se puede decir que los acontecimientos socioespaciales o socioambientales existen en la medida en que los medios de comunicación los producen. A esta premisa, en el siglo XXI, hay que agregar como actores productores y reproductores de acontecimientos a los usuarios de redes sociales, ya que estas se integran a la vida colectiva como fuente de información o desinformación (como acontece con las fake news), incluso de elaboración (periodismo ciudadano). Indagar en los contenidos que se vuelcan o proponen en las redes por parte de los afectados a un conflicto socioambiental (demandados y demandantes) permite tener una idea aproximada del grado de influencia que ejercen los medios en la interpretación colectiva e individual de los hechos, de los antagonistas y protagonistas, y de las valoraciones que subyacen al territorio donde se produce la disputa. El flujo de la información circula de diferentes maneras debido a la posibilidad de que existan varios emisores (medios de prensa, agencias de gobierno, 
poder judicial) y receptores (público en general, comunidades, individuos) que, al mismo tiempo, decodifican el mensaje, lo reelaboran (por ejemplo, cuando se publica una noticia en un medio digital con la opinión de los lectores) y utilizan diferentes canales para remitirlos con su propia posición (por ejemplo, cuando se comparte la noticia con otros usuarios de una red social), asumiendo, en parte, el rol de emisores.

Un ejemplo latinoamericano, sobre la cobertura periodística de un conflicto socioambiental, fueron los incendios en la selva amazónica en el año 2019. En la Figura 8 se puede leer unos de los titulares de O'Globo sobre el caso: «Ministro de Medio Ambiente afirma que parte de los incendios en Amazonas es intencional». Se trata del grupo mediático liberal y conservador con mayor influencia política en Brasil. En la misma figura, sobre el mismo conflicto, el periódico Gazeta Operária titula: «Por el lucro, el capitalismo mata personas, mata bosques, mata animales». Se trata de la publicación de la organización política, gremial y cultural «Luta Pelo Socialismo», con un perfil militante, abordando el caso desde la crítica al sistema económico. Por último, se puede leer la nota de prensa de la organización ecologista Greenpeace Brasil titulada: «Ricardo Salles debe ser retirado inmediatamente del Ministerio de Medio Ambiente». La denuncia es a la administración y no al régimen social, como el caso anterior.

Figura 8. Titulares de la prensa brasileńa sobre los incendios en el Amazonas.

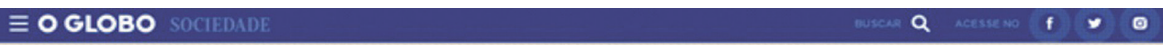

Ministro do Meio Ambiente afirma que parte dos incêndios na Amazônia é intencional

No inicio do dia, Bolsonaro afirmou que queimadas teriam sido provocadas por ONGs insatisfoitas com corte de verbas

onosos

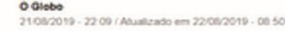

(ㄱ)(ㅇ)(ㄴ)
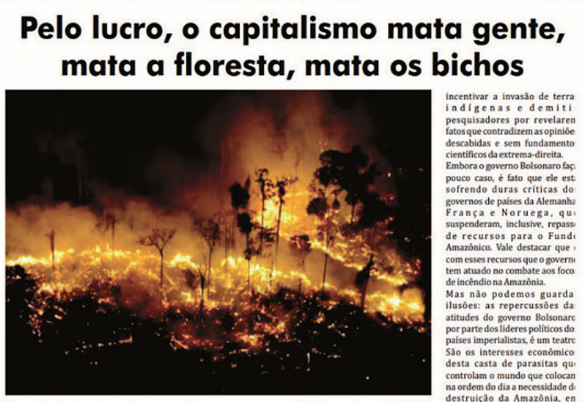

Fuente: O’Globo, Gazeta Operária y Greenpeace.

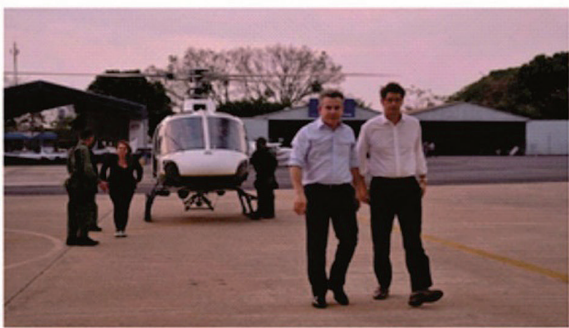

Ricardo Salles deve ser retirado imediatamente do Ministério de Meio Ambiente

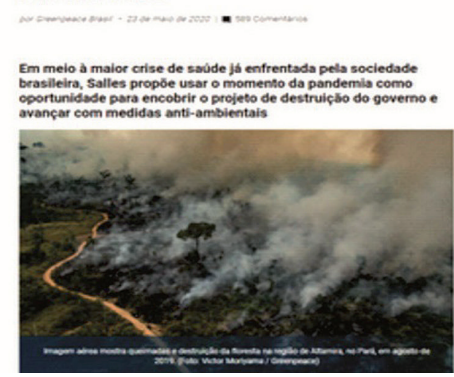


En un segundo paso, en lo posible, es conveniente realizar trabajos de relevamiento en los territorios afectados a un conflicto socioambiental, conocer in situ el problema, efectuar observaciones y anotaciones sobre los acontecimientos e hipotetizar sobre cómo las acciones puestas en cuestionamiento condicionan o condicionarían (en el caso que el conflicto se haya desatado por un proyecto) las relaciones socioespaciales y socioambientales preexistentes. Como sustituto o respaldo del trabajo de campo, en el caso de que se quiera estudiar un conflicto fuera del alcance del alumnado, pueden sugerirse y seleccionarse diversas fuentes secundarias como imágenes fotográficas, imágenes satelitales, videos, audiovisuales, películas documentales sobre el caso, crónicas literarias, filmaciones realizadas con diferentes dispositivos por afectados, investigaciones y fallos judiciales, folletos, etc.

Con la información reunida, el alumno estaría en condiciones de identificar el PI en el conflicto socioambiental, evaluar si las acciones que ejercen las transformaciones territoriales han desencadenado un trauma territorial y analizar cuál es el FF de la fuerza TDR. Al mismo tiempo, en esta etapa de análisis de la información, tienen que ser definidos cuatro tipos de actores socio-territoriales presentes en los conflictos socioambientales:

i. Actores demandados y responsabilizados (ADR): A estos se les atribuye la responsabilidad del estado de conflictividad, ya sea por acción o inacción. Por lo general, son los que ejercen el dominio territorial, principalmente, mediante el derecho en términos de propiedad privada o estatal. Por ejemplo, en el caso del conflicto socioambiental por la expansión territorial de la soja en Paraguay son los agribusiness (nacionales y extranjeros), las corporaciones multinacionales que proveen insumos (paquetes tecnológicos) y el Estado Paraguayo que custodia los intereses de los empresarios ligados a la producción de soja. En este grupo, se agregan los sectores, si los hubiere, que respaldan el accionar denunciado, en el caso mencionado podemos señalar la Unión Industrial Paraguaya y la Asociación Nacional Republicana - Partido Colorado (ANR-PC), coalición política conservadora-liberal, actualmente al frente del gobierno nacional.

ii. Actores demandantes y contendientes (ADC): Son aquellos que inician el conflicto por disenso y oposición al accionar de los primeros, son los que expresan la defensa al medio ambiente, reivindican el territorio afectado por los intereses de los ADR y confrontan las razones de estos. Por ejemplo, siguiendo el caso citado, son ADC los campesinos paraguayos y brasileños (que habitan en Paraguay) expulsados de sus tierras por las plantaciones de soja, sobre todo aquellos agrupados en organizaciones o federaciones desde las cuáles reclaman por el derecho a la tierra y la reforma agraria. Se pueden sumar, como parte de esta tipología, los representantes legales (abogados ambientalistas de las organizaciones campesinas) y los adherentes: partidos políticos ecologistas, centroizquierda o de izquierda; guerrillas campesinas; ONG ambientalistas; diferentes personalidades; que se oponen al avance de la soja por sus consecuencias socioambientales.

iii. Actores especialistas y comunicacionales (AEC): En este grupo están los actores que producen datos científicos sobre la problemática, los que la analizan en base a la jurisprudencia y los medios de comunicación que difunden los acontecimientos. La información y datos generados y/o difundidos por los AEC pueden ser de utilidad para los ADR 
o ADC. En el caso del conflicto socioambiental por la soja en Paraguay, desde los ámbitos académicos, tanto nacionales como extranjeros, se han desarrollado investigaciones que dimensionan el problema ambiental, social y de salud que trae aparejado la expansión del cultivo. También, hay informes y trabajos de investigación que exponen sobre los beneficios del monocultivo para un país con una economía pequeña, como es la de Paraguay. En los medios de comunicación acontece lo mismo, mientras corporaciones mediáticas contribuyen al conflicto reforzando la representación negativa de la protesta social, otros medios son aliados de los ADR. Ante la concentración empresarial en la producción de acontecimientos periodísticos, generalmente, las propias organizaciones campesinas promueven sus propios medios alternativos para poder generar sus contenidos en canales de comunicación más directos, pero con menos llegada al conjunto de la población.

iv. Actores judiciales, ejecutivos y parlamentarios (AJEP): Estos representan los tres poderes del Estado Moderno, son los actores con autoridad institucional para pronunciarse a favor o en contra de un reclamo, promover canales de diálogo, dictar medidas o leyes, definir límites, incitar o exigir el acuerdo de las partes, reprimir a los ADC, sancionar a los ADR, censurar a los AIC, etc.

Una vez obtenida la información general sobre un conflicto socioambiental para estudiarlo en clave territorial la primera tarea es su delimitación espacio-temporal. Esto busca responder las preguntas respecto de cuándo, dónde, hasta dónde, cuáles son los límites y la escala del conflicto. Acto seguido, hay que identificar cómo está configurado (material y simbólicamente) el recorte territorial en el que se desenvuelve el conflicto. Esto nos aporta a las respuestas de preguntas tales como por qué en ese territorio, o en forma más detallada: qué propiedades (recursos) contiene el territorio para que se presente tal conflicto socioambiental. Respecto al orden simbólico, es importante indagar sobre las valoraciones que los diferentes actores realizan con el territorio afectado, indagando si predominan relaciones espaciales fílicas, fálicas, patrimonialistas, privatistas, exclusivistas, ecocéntricas, tecnocéntricas, etc.

Después del primer conjunto de interrogantes sobre la construcción territorial del conflicto socioambiental, hay que pasar a un segundo grupo de preguntas en las que se examine la naturaleza de las acciones que impactan en el territorio y las consecuencias socioambientales que desatan el estado de conflictividad. Esto último, es lo que nos introduce a la detección y análisis de la fuerza TDR, al responderse si la acción es proyectiva o se trata de un hecho consumado, qué factor influye (FF) más en la decisión de accionar o proyectar (fuerza TDR) en el territorio, cuál es el problema socioambiental que se ha generado (o se supone que se generaría) y que ha instalado un estado de conflictividad territorial y qué características tiene. En función de la vinculación de la fractura ecosistémica con lo territorial, hay que responder a interrogantes que refieran a cómo afecta el problema al ecosistema, al hábitat y cuerpo humano, a las diferentes especies, a los factores bióticos y abióticos; y qué tipo de identidades territoriales se defienden ante la amenazada de ser desarticuladas por el accionar de fuerzas que promueven problemáticas socioambientales. 
Identificados los actores que intervienen en la contienda las preguntas que orientan la caracterización de los mismos son (Figura 9): quiénes son, a qué tipología pertenecen, qué roles tienen, cuáles son los motivos para intervenir en el territorio o resistir la intervención, qué tipo de valoraciones realizan respecto del espacio resinificado por la contienda, cómo se organizan, qué proponen, y si intervienen en la gestión formal o informal del territorio y cómo efectúan tal función.

Figura 9. Ejemplo de una tabla, collage y/o croquis en el que se simplifica el conflicto socioambiental producto del avance de la frontera sojera en Paraguay, identificando el PI $\mathrm{y}$ los diferentes actores socioterritoriales que intervienen.

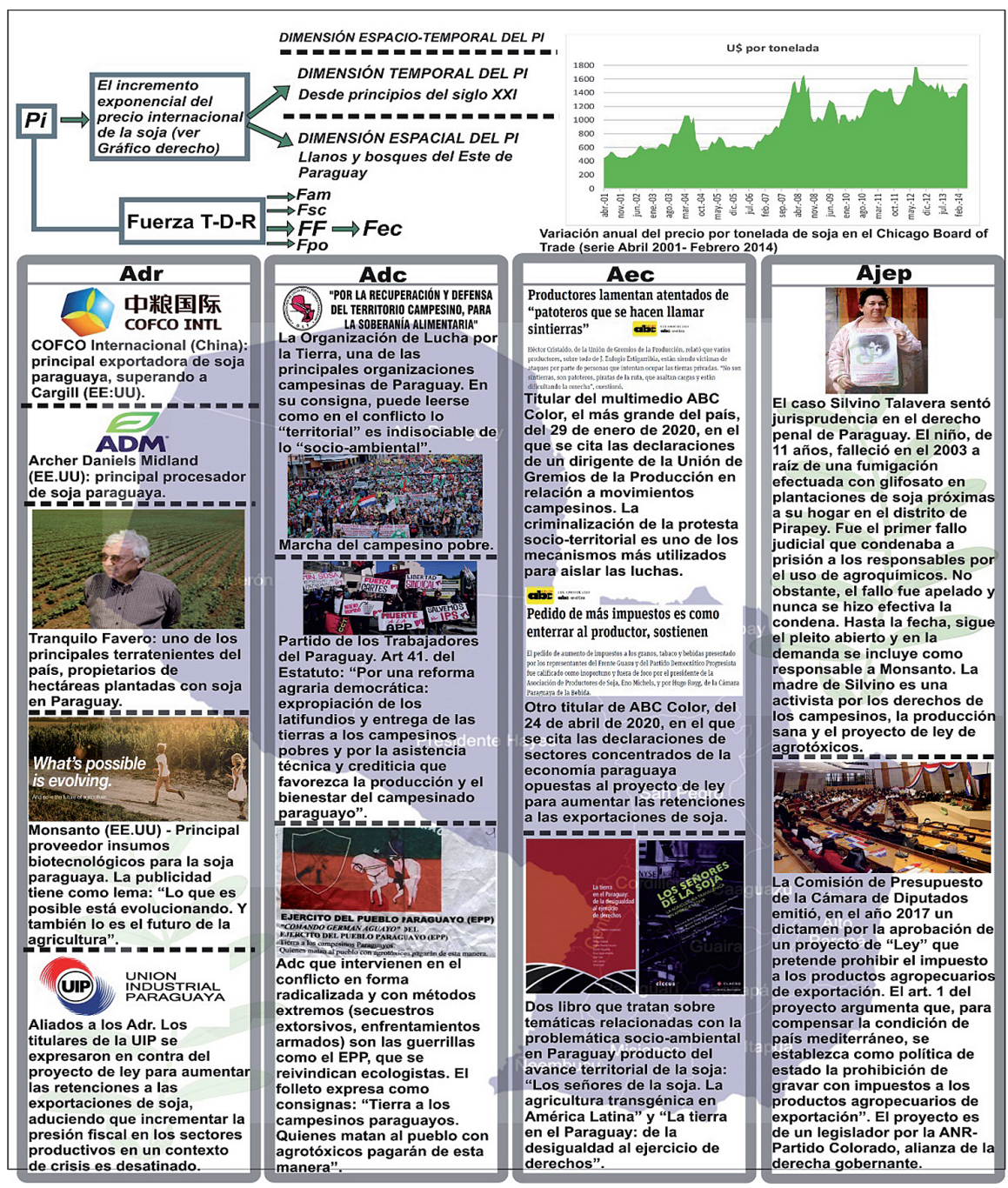

Fuente: elaboración propia sobre la base de múltiples fuentes. 
Conviene exponer los resultados en una tabla general, cuadro sinóptico u otro esquema gráfico útil para la organización del material recabado y las respuestas a las preguntas formuladas. Esta forma de presentación contribuye no solo a simplificar, sino también a comparar con otros casos y dar cuenta de los denominadores comunes que se presentan en los conflictos socioambientales y del tipo de respuesta socioterritorial. Se encabeza la tabla con la exposición del PI, para luego disgregar el análisis en el modo en que repercuten las transformaciones materializadas o planeadas en los diferentes factores que hacen a la dinámica del territorio y, finalmente, cómo el problema que genera determinada intervención en el territorio (o que se supone que lo hará, en el caso de que se trate de un proyecto) siembra un estado de conflictividad. Esto significa responder, a grandes rasgos, qué cambios se introducen, por qué son problemas socioambientales y qué reacciones emergen de las sociedades involucradas o afectadas. Cabe remarcar que no solo se puede trabajar con las acciones materializadas, sino también con lo planeado o proyectado, debido a que los impactos pueden ser calculados sobre intervenciones territoriales concretadas que sean analógicamente homologables a las anunciadas, por un conjunto de cualidades (misma región, diseño arquitectónico, función, etc.). En efecto, tanto las transformaciones concretas como las potenciales son fuente de conflictividad, y, por tal motivo, ambas deben ser estudiadas.

\section{Conclusiones}

Este ensayo sobre herramientas conceptuales y didácticas para impartir la enseñanza (en todos los niveles educativos) de un tema central en la agenda pública del siglo XXI, como lo es la crisis socioambiental, pretendió contribuir a una lectura crítica del mundo (Freire, 2000) a través de una guía metodológica para llevar la problemática tratada a las aulas. Más aún, cuando asistimos, en tiempos de pandemia, a una etapa en la cual el sistema socioeconómico fracasa para dar respuestas inmediatas a urgencias vitales. Lo "geográfico» frente a esta catástrofe global no es un dato menor o solo un mapa en el que se plasman el conteo de los casos por COVID-19 y los fallecimientos por país y región. El surgimiento de nuevos virus producto de la pérdida de hábitats silvestres y las fracturas ecosistémicas por la intervención del capital, la concentración de la población en enormes núcleos urbanos, el hacinamiento en asentamientos de emergencia que actúan como principales focos de contagio, la polarización socioespacial que expresa las disparidades para enfrentar la crisis sanitaria, el racismo emergente que se recrudece ante la irrupción y reforzamiento de estados policiales, las deudas externas, y eternas usurarias y fraudulentas que obstruyen la posibilidad de invertir en los sistemas de prevención y atención, el problema de la distribución del agua potable en los espacios más vulnerabilizados, la detonación de los sistemas de salud y educación públicos, entre tantos, no son temas ajenos al campo del estudio. 
Se puede proponer y propiciar iniciar un debate serio y honesto sobre una "geografía del conflicto", que centre su análisis y oficio en el encuentro, en un mismo espacio, de dos o más lógicas que confrontan en una disputa que tiene una notoria connotación territorial. Entonces, lo que atiende esta propuesta disciplinaria es la pugna entre actores territorializados, que pretenden estarlo (territorializarse) o que ejercen su poder desde un comando ajeno al territorio (extraterritoriales). Como lo venimos demostrando en este artículo, la conflictividad socioambiental se presenta como una arista posible para el abordaje y aprendizaje geográfico, y como un dato geopolítico que refleja que ante las profundas desigualdades socioambientales y socioterritoriales, los sectores afectados $\mathrm{y}$ vulnerabilizados de todas las sociedades del mundo no permanecen pasivos.

\section{REFERENCIAS}

Acselrad, H. (2010). Ambientalização das lutas sociais -o caso do movimiento por justiça ambiental. Estudos Avançados, 24(68), 103-119. https://doi.org/10.1590/S010340142010000100010

Ardrey, R. (2014). The Territorial Imperative: A Personal Inquiry into the Animal Origins of Property and Nations. Memphis: StoryDesign LTD.

Darwin, C. (2014). A Origem das Espécies. São Paulo: Martín Claret Editora.

Di Méo, G. (1998). Géographie sociale et territories. París: Nathan

Carrasco, A. (2011). El glifosato: ¡es parte de un modelo eugenésico? Salud Colectiva, 7(2), 129-133. https://doi.org/10.18294/sc.2011.368

Castillo, R. (2013). Contaminación del aire en la ciudad de Ilo: Crónica de la espiral histórica de un conflicto ambiental local. Revista PAIDEIA XXI, 2(3), 69-80.

Engels, F. (2009). The condition of the working class in England in 1844. Londres: Penguin Classics. https://doi.org/10.1017/CBO9780511792700

Fernandes, B. (2005). Movimentos socioterritoriais e movimentos socioespaciais. Contribuiçáo teórica para uma leitura geográfica dos movimentos sociais. OSAL, 6(16), 273-283.

Foucault, M. (1990). Les mots et les choses: Une archéologie des sciences humaines. París: Gallimard. https://doi.org/10.14375/NP.9782070293353

Freire, P. (2000). Pedagogia da indignaçâo: cartas pedagógicas e outros escritos. Sáo Paulo: UNESP. https://doi.org/10.1590/S1414-32832001000100016

Gramsci, A. (1996). Il materialismo storico e la filosofia di Benedetto Croce. Roma: Editori Riuniti.

Haesbaert, R. (2004). O mito da desterritorialização: do "fim dos territórios" à multiterritorialidade. Río de Janeiro: Bertrand.

Hernández, F \& Furlan, A. (2016). El discurso como ejercicio de la territorialidad. Cuadernos Geográficos, 55(1), 59-91. 
Leff, E. (2004). Racionalidad ambiental. La reapropiación social de la naturaleza. México: Siglo XXI.

O'Connor, J. (1998). Natural Causes: Essays in Ecological Marxism. Nueva York: Guilford Press.

Porto Gonçalves, C. (2005). Os (des) caminhos do meio ambiente. São Paulo: Contexto.

Pujol, D. (1987). Naturaleza, espacio y sociedad: notas acerca de Uneven Development, de Neil Smith. Documents dlAnilisi Geogrifica, 11, 137-144.

Raffestin, C. (2019). Pour une géographie du pouvoir. Lyon: ENS Éditions. https://doi. org/10.4000/books.enseditions.7627

Ratzel, F. (1987). La Geographiepolitique. Les concepts fondamentaux. París: Librairie Arthème Fayard.

Redacción (2012). La polémica represa en la Patagonia chilena recibe el visto bueno de la Justicia. 5 de abril de 2012. BBC Mundo. Recuperado de https://www.bbc.com/ mundo/noticias/2012/04/120404_chile_represa_patagonia_aysen_fp

Reboratti, C (2006). La naturaleza y nosotros: el problema ambiental. Buenos Aires: Capital Intelectual.

Reyes, S. y Rodríguez, J. (2015). Proyecto Hidroaysén: capitalismo extractivista, regulación estatal y acción colectiva en la Patagonia. Polis, 14(40), 439-467. https://doi. org/10.4067/S0718-65682015000100021

Sabatini, F. (1994). Conflictos ambientales entre la globalización y la sociedad civil - Espiral histórica de conflictos ambientales. Santiago de Chile: Publicaciones CIPMA.

San Martín, R. (2008). Contra la objetividad el mito de la neutralidad periodística y las alternativas para repensarlo. Perspectivas de la Comunicación, 1(1), 73-80.

Santos, M. (1997). A natureza do espaço. Técnica e tempo. Razâo e emoçâo. São Paulo: Hucitec.

Suprema Corte de Chile (2012). Causa: Antonio Horvath Kiss y otros contra Comisión de Evaluación Ambiental de la Región de Aysén. Rol No 10.220. Fallo del 4 de abril de la Tercera Sala. Santiago de Chile: Poder Judicial de la República de Chile.

Svampa, M. (2012). Consenso de los commodities, giro ecoterritorial y pensamiento crítico en América Latina. OSAL, 7(32), 15-38.

Svampa, M. (2017). Del cambio de época al fin de ciclo. Gobiernos progresistas, extractivismo y movimientos sociales en América Latina. Buenos Aires: Edhasa.

Tuan, Y. (1990). Topophilia: A Study of Environmental Perception, Attitudes and Values. Nueva York: Columbia University Press.

Verón, E. (1981). Construire l'événement. Les médias et l'accident de Three Mile Island. París: Editions de Minuit.

Wagner, L. (2010). Problemas ambientales y conflicto social en Argentina. Movimientos socioambientales en Mendoza. La defensa del agua y el rechazo a la megaminería en los inicios del siglo XXI. Tesis de doctorado. Bernal: Universidad Nacional de Quilmes. 